\title{
Development of a cloud particle sensor for radiosonde sounding
}

\author{
Masatomo Fujiwara ${ }^{1,2}$, Takuji Sugidachi ${ }^{1, a}$, Toru Arai ${ }^{1, b}$, Kensaku Shimizu ${ }^{3}$, Mayumi Hayashi ${ }^{4}$, Yasuhisa Noma ${ }^{4}$, \\ Hideaki Kawagita $^{4}$, Kazuo Sagara $^{4}$, Taro Nakagawa ${ }^{5}$, Satoshi Okumura ${ }^{5}$, Yoichi Inai ${ }^{2, \mathrm{c}}$, Takashi Shibata ${ }^{6}$, \\ Suginori Iwasaki ${ }^{7}$, and Atsushi Shimizu ${ }^{8}$ \\ ${ }^{1}$ Graduate School of Environmental Science, Hokkaido University, Sapporo, 060-0810, Japan \\ ${ }^{2}$ Faculty of Environmental Earth Science, Hokkaido University, Sapporo, 060-0810, Japan \\ ${ }^{3}$ Meisei Electric Co., Ltd, Isesaki, 372-8585, Japan \\ ${ }^{4}$ Shinyei Technology Co., Ltd, Kobe, 650-0047, Japan \\ ${ }^{5}$ Shinyei Kaisha, Kobe, 651-0178, Japan \\ ${ }^{6}$ Graduate School of Environmental Studies, Nagoya University, Nagoya, 464-8601, Japan \\ ${ }^{7}$ Department of Earth and Ocean Sciences, National Defense Academy, Yokosuka, 239-8686, Japan \\ ${ }^{8}$ National Institute for Environmental Studies, Tsukuba, 305-8506, Japan \\ ${ }^{a}$ now at: Meisei Electric Co., Ltd, Isesaki, 372-8585, Japan \\ ${ }^{b}$ now at: MTG Co., Ltd, Nagoya, 453-0041, Japan \\ ${ }^{c}$ now at: Graduate School of Science, Tohoku University, 980-8578, Japan
}

Correspondence to: Masatomo Fujiwara (fuji@ees.hokudai.ac.jp)

Received: 19 May 2016 - Published in Atmos. Meas. Tech. Discuss.: 24 May 2016

Revised: 10 November 2016 - Accepted: 18 November 2016 - Published: 9 December 2016

\begin{abstract}
A meteorological balloon-borne cloud sensor called the cloud particle sensor (CPS) has been developed. The CPS is equipped with a diode laser at $\sim 790 \mathrm{~nm}$ and two photodetectors, with a polarization plate in front of one of the detectors, to count the number of particles per second and to obtain the cloud-phase information (i.e. liquid, ice, or mixed). The lower detection limit for particle size was evaluated in laboratory experiments as $\sim 2 \mu \mathrm{m}$ diameter for water droplets. For the current model the output voltage often saturates for water droplets with diameter equal to or greater than $\sim 80 \mu \mathrm{m}$. The upper limit of the directly measured particle number concentration is $\sim 2 \mathrm{~cm}^{-3}\left(2 \times 10^{3} \mathrm{~L}^{-1}\right)$, which is determined by the volume of the detection area of the instrument. In a cloud layer with a number concentration higher than this value, particle signal overlap and multiple scattering of light occur within the detection area, resulting in a counting loss, though a partial correction may be possible using the particle signal width data. The CPS is currently interfaced with either a Meisei RS-06G radiosonde or a Meisei RS-11G radiosonde that measures vertical profiles of temperature, relative humidity, height, pressure, and horizontal winds. Twenty-five test flights have been made between 2012 and 2015 at midlatitude and tropical sites. In this paper, re-
\end{abstract}

sults from four flights are discussed in detail. A simultaneous flight of two CPSs with different instrumental configurations confirmed the robustness of the technique. At a midlatitude site, a profile containing, from low to high altitude, water clouds, mixed-phase clouds, and ice clouds was successfully obtained. In the tropics, vertically thick cloud layers in the middle to upper troposphere and vertically thin cirrus layers in the upper troposphere were successfully detected in two separate flights. The data quality is much better at night, dusk, and dawn than during the daytime because strong sunlight affects the measurements of scattered light.

\section{Introduction}

Clouds play various roles in the weather and climate through latent heat transport, precipitation and the hydrological cycle, and shortwave and longwave radiative processes. Clouds are characterized by various microphysical parameters such as phase (liquid or ice), particle size distribution, number concentration, water content, and particle shape (e.g. Pruppacher and Klett, 1997), as well as various dynamical parameters (e.g. cloud cover, cloud type, and vertical extent). 
There are various platforms and sensors for measuring cloud properties. Ground-based and satellite-borne remote sensing instruments mainly provide macroscopic features of cloud distribution, with some instruments giving estimates of microphysical properties, while in situ instruments on aircraft and meteorological balloons provide microphysical properties of clouds, often together with air temperature and humidity measurements from sensors on the same platform.

Meteorological balloons are low-cost devices for upperair sounding. Radiosondes on the balloons measure vertical profiles continuously from the surface up to the middle stratosphere in $\sim 100 \mathrm{~min}$. The radiosonde temperature and humidity measurements, including those from balloon-borne special hygrometers, have been well characterized by regular and special intercomparison campaigns (e.g. Nash et al., 2011; Vömel et al., 2016). The typical balloon ascent rate is $\sim 5 \mathrm{~m} \mathrm{~s}^{-1}$, which is much smaller than the speed of aircrafts, easing some of the technical challenges that aircraft instruments may face (e.g. shattering of ice crystals; Baumgardner et al., 2012). However, balloon instruments need to be disposable, operable with small batteries, and of small mass. These factors may result in technical challenges when developing balloon-borne cloud particle instruments. Nevertheless, balloon-borne instruments are potentially useful for high-frequency measurements of cloud microphysical properties. Among such instruments, both the hydrometeor videosonde (HYVIS) (Murakami and Matsuo, 1990; Orikasa et al., 2005, 2013) and the balloon-borne Formvar replicators (Magono and Tazawa, 1966; Miloshevich and Heymsfield, 1997) continuously collect particles on a filmstrip during balloon ascent. HYVIS continuously transmits video images of the film surface to the ground, while the film with ice crystal replica is obtained upon recovery of the Formvar instrument. This type of particle collector requires knowledge of the collection efficiency on the film for quantitative interpretation of the results. In another instrument, the videosonde (e.g. Takahashi, 1990, 2006; Suzuki et al., 2014), the primary component is a video camera with flash lamp that takes video images of falling particles introduced into the instrument; the studies by Takahashi also use an induction ring to measure the electric charge of the particles. The videosonde has been primarily used for studies of precipitating clouds in the Asian monsoon region (Takahashi, 2006), while the HYVIS has been used for studies of midlatitude cirrus clouds (Orikasa et al., 2013; Orikasa and Murakami, 2015). The balloonborne particle-measuring instrument, called the backscattersonde (Rosen and Kjome, 1991), shines a flash-lamp beam periodically on the ambient air and measures the amount of backscattered light. This instrument has been extensively used for studies of polar stratospheric clouds (PSCs) and stratospheric aerosols (e.g. Suortti et al., 2001) but is also capable of measuring tropospheric clouds and aerosols. Based on the same principle, a much smaller instrument called the COBALD (Compact Optical Backscatter AerosoL Detector) was recently developed and used for cirrus studies (Brabec et al., 2012; Hasebe et al., 2013). The backscattersonde and COBALD are used only at night because they measure artificial light scattered from outside the instrument. Finally, a balloon-borne optical particle counter (OPC) has been used for studies on PSCs (Hayashi et al., 1998) and on cirrus clouds and aerosols in the tropical tropopause layer (Iwasaki et al., 2007; Shibata et al., 2012). This instrument uses an inlet tube and a gear pump to introduce air into a scattering cell where a laser diode and a silicon photodiode are used to characterize the size distribution of aerosol particles.

The masses of the balloon-borne particle instruments described above range from 1 to $6 \mathrm{~kg}$, except for COBALD whose mass is $500 \mathrm{~g}$; this is much greater than the few hundred grams for recent operational radiosondes. Also, as these are special instruments developed by researchers, in most cases they are available only under collaboration with those researchers. In practice, it is not easy to introduce and use these instruments as extensively as radiosondes and ozonesondes for both operational and research purposes.

In this paper, we present the results from a newly developed, small-mass $(\sim 200 \mathrm{~g})$ instrument called the cloud particle sensor (CPS) flown in combination with a radiosonde. The CPS uses the air flow associated with the balloon ascent or descent to introduce air into a detection area within the instrument where a diode laser and two photodetectors are used to count the number of cloud particles and to characterize their phase using the polarization information. The CPS is based on a pollen sensor, the PS2, developed by the Shinyei Technology Co., Ltd for a surface, multiple-point pollen-particle measurement network. We modified the PS2 for upper-air cloud particle soundings, developed an interface board for the Meisei RS-06G radiosonde (Nash et al., 2011) and its upgraded version, Meisei RS-11G radiosonde, and made several laboratory experiments to characterize the capabilities and limitations of the instrument. We have made 25 test flights in total in Japan, Palau, and Indonesia during the period between 2012 and 2015. In this paper, we will show the results for four cases, i.e. midlatitude stratus (and cirrus) clouds associated with a low-pressure system, midlatitude precipitating clouds including mixed-phase clouds, tropical mid- and upper tropospheric thick cloud layers, and tropical upper tropospheric thin cirrus layers.

It is noted that recently, there appeared several aircraft instruments that utilize the polarization information to characterize cloud particle phase, such as the Cloud Aerosol Spectrometer with Polarization (CASPOL; e.g. Nichman et al., 2016), the Small Ice Detector mark 2 (SID-2; e.g. Cotton et al., 2010), and the Cloud Particle Spectrometer with Polarization Detection (CPSPD; Baumgardner et al., 2014). See also Baumgardner et al. (2012) and Wendisch and Brenguier (2013) for recent developments on the aircraft instruments. In addition, in the lidar community, the polarization information has been used for cloud measurements since the 1970s (Schotland et al., 1971; see also Sassen, 1991). It is also noted here that possible scientific applications of the 


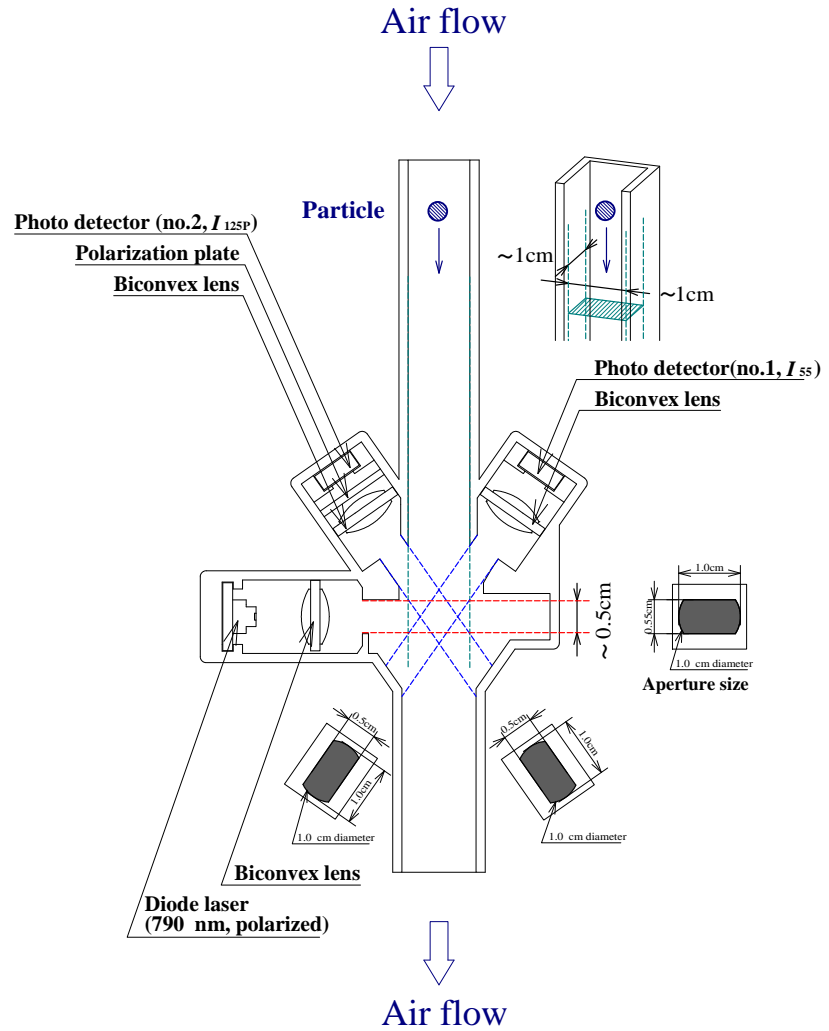

Figure 1. Schematic diagram of the CPS (the latest version). The diode laser, lenses, and two detectors (nos. 1 and 2) are shown, together with the polarization plate for detector no. 2 . Note that the laser device, scattering particle, and the two detectors are placed within the same plane, and the polarization of the incident light is parallel to this plane. Also shown is the information on the detection area (with red, blue, and green dashed lines and with the views through the slits and lenses).

CPS include subvisual cirrus cloud processes in the tropical tropopause layer (TTL) (e.g. Iwasaki et al., 2004, 2007; Fujiwara et al., 2009; Shibata et al., 2007, 2012; Inai et al., 2012), radiosonde relative humidity (RH) sensor validation during radiosonde intercomparison campaigns, applications for dropsonde systems (by further modifying the current CPS) to observe precipitating clouds (e.g. in association with typhoons), and applications for long-duration balloon systems flying in the upper troposphere and lower stratosphere (UTLS), among others.

The remainder of this paper is organized as follows. The CPS and its interfacing with the Meisei radiosondes are described in Sect. 2. Results from four selected flights are described and discussed in Sect. 3, showing the capabilities and limitations of the CPS. Section 4 lists the main conclusions.

\section{Instrumentation}

\subsection{Description of the CPS}

Figure 1 shows a schematic diagram of the CPS. A nearinfrared diode laser is used as a source of linearly polarized light. (The polarization is parallel to the scattering plane formed by the incident light, particle, and the two detectors.) The peak wavelength of the laser device has a nominal value of $790 \mathrm{~nm}$, with individual devices varying between 775 and $810 \mathrm{~nm}$, with a full width at half maximum of roughly $5 \mathrm{~nm}$. Two silicon photodiodes are placed at angles of $55^{\circ}$ (detector no. 1) and $125^{\circ}$ (detector no. 2) with respect to the sourcelight direction. A polarization plate is placed in front of detector no. 2 , so that detector no. 2 only receives light polarized perpendicularly to the source light. Lenses and slits are placed in front of the light source and the two detectors. The slit in front of the light source is $0.55 \mathrm{~cm} \times 1.0 \mathrm{~cm}$, while the slits in front of the two detectors are $0.50 \mathrm{~cm} \times 1.0 \mathrm{~cm}$. Because of the lens and slits, detectors nos. 1 and 2 actually collect light scattered at $55^{\circ} \pm 10^{\circ}$ and $125^{\circ} \pm 10^{\circ}$, respectively. The cross section of the detection area that the detectors effectively see is roughly estimated as $\sim 1 \mathrm{~cm} \times 1 \mathrm{~cm}$, while its vertical extent is $\sim 0.5 \mathrm{~cm}$ (see Fig. 1). Thus, the volume of the detection area is $\sim 0.5 \mathrm{~cm}^{3}$. The cross section of the air inlet is $1.0 \mathrm{~cm} \times 1.2 \mathrm{~cm}$. A particle that passes through the detection area scatters the laser light, and the two detectors receive the scattered light signal and thus count that particle. Note that particles are not constrained to go through a particular point of the detection area. Uncertainty arising due to this treatment is shown in the results from standard particle experiments described in Appendix A.

The particle signal voltages from the two detectors ( $I_{55}$ for no. 1 and $I_{125 \mathrm{p}}$ for no. 2) range from 0 to $7.5 \mathrm{~V}$ with a resolution of $0.03 \mathrm{~V}$. During the factory calibration, both are electronically adjusted to $2.5 \pm 0.5 \mathrm{~V}$ using rough-surface particles of 30-40 $\mu \mathrm{m}$ diameter (with the polarization plate situated in front of detector no. 2). The rough-surface particles of $30-40 \mu \mathrm{m}$ diameter are the spores of the Lycopodium clavatum Linnaeus provided by the Association of Powder Process Industry and Engineering (APPIE), Japan. Other roughsurface particles may also work; the key point is that we use certain particles so that we can calibrate the two detectors after the instrument is fully assembled. The sensitivity of the two detectors is differently adjusted so that the calibration particles give the same $I_{55}$ and $I_{125 p}$ values on average (using 251 particle data). Typically, detector no. 2 is about three times more sensitive than detector no. 1 ; this is consistent with the fact that the polarization plate used has 34$35 \%$ transmittance. The original sampling frequency of the $I_{55}$ and $I_{125 \mathrm{p}}$ measurements is $11 \mathrm{kHz}$ (i.e. virtually continuous), and a particle is detected when $I_{55}$ exceeds a threshold value of $0.3 \mathrm{~V}$. Extensive laboratory experiments were conducted to determine the lower detection limit of the particle size and the relationship between $I_{55}$ and water droplet 
diameter (Appendix A). Three CPS instruments were used to measure $I_{55}$ for $1 \mu \mathrm{m}$ diameter polystyrene particles, 2,5 , 10 , and $20 \mu \mathrm{m}$ diameter borosilicate glass particles, and 30 , 60 , and $100 \mu \mathrm{m}$ diameter soda lime glass particles. The CPS was unable to detect $1 \mu \mathrm{m}$ diameter polystyrene particles but could detect $2 \mu \mathrm{m}$ diameter borosilicate glass particles. Also, the CPS often gives saturated outputs $(\sim 7.5 \mathrm{~V})$ for 60 and $100 \mu \mathrm{m}$ diameter soda lime glass particles. Mie scattering theory (Bohren and Huffman, 1998) determines the scattered light intensity as a function of the size and refractive index of a spherical particle, scattering angle, wavelength of the light, and polarization. This theory is used to convert the diameter of the particles used in the experiments to that of water droplets and spherical ice particles. In short, for the current model of CPS, the lower detection limit for water droplets is $\sim 2 \mu \mathrm{m}$ diameter, and the output voltage often saturates for water droplets equal to or greater than $\sim 80 \mu \mathrm{m}$ diameter. See Appendix A for the detailed results of the experiments including the relationship obtained between $I_{55}$ and the diameter of water droplets and spherical ice particles.

To characterize the phase of the cloud particle (i.e. liquid or ice), the degree of polarization (DOP) is defined for this paper as

$\mathrm{DOP}=\frac{I_{55}-I_{125 \mathrm{p}}}{I_{55}+I_{125 \mathrm{p}}}$.

DOP should be close to unity for spherical (i.e. liquid) particles because their $I_{125 \mathrm{p}}$ would be close to zero. In contrast, DOP would take various values between -1 and +1 for nonspherical ice crystals. The actual DOP distribution depends on the uncertainty in the factory calibration, the shape of measured particles, and the particle path in the detection area, among others. See Sect. 3 for the actual flight results and Appendix A for the results from the laboratory experiments using standard spherical particles. The conclusions are as follows. When the DOP value is negative, the particle is ice. When the DOP value is positive but less than $\sim 0.3$, the particle is most likely ice. When the DOP value is more than $\sim 0.3$, the particle is water in many cases, but there is a chance that it is ice (because DOP can take values between -1 and +1 for ice particles; as shown in the flight results in Sect. 3); for the final judgement, the DOP statistics of the cloud layer to which the particle is belong and the simultaneous temperature value should also be taken into account (as done in Sect. 3). It should also be noted that the characterization of particle phase using DOP might be possible even for large particles (i.e. $>\sim 80 \mu \mathrm{m}$ ) when $I_{55}$ is saturated. This is because for water droplets, $I_{125 p}$ for those large particles would still be close to zero and thus DOP would be close to unity, while for ice crystals, DOP would take various values. See Appendix A and Fig. A2 for the case of 60 and $100 \mu \mathrm{m}$ diameter soda lime glass particles (corresponding to $\sim 80$ and $\sim 130 \mu \mathrm{m}$ diameter water droplets, respectively). Finally, it is noted that coarse-mode aerosol particles may give similar DOP values to ice particles.
The CPS also monitors the particle signal width, i.e. the time interval of each particle signal (between the time when $I_{55}$ first exceeds $0.3 \mathrm{~V}$ and the time when $I_{55}$ falls below $0.3 \mathrm{~V}$ ). The signal width data can be used to monitor potential particle overlap in the case of dense cloud layers. Too long a signal width value may indicate too many particles overlapping in the detection area and thus a substantial loss in particle count. In such a case, multiple light scattering would also occur to complicate the particle measurements ( $I_{55}$ may be saturated, i.e. at $\sim 7.5 \mathrm{~V})$. See Sect. 2.3 for the full discussion on the number concentration measurements by the CPS. The signal width data may also be used to infer the flow speed in the detection area whose vertical extent is $\sim 0.5 \mathrm{~cm}$. As the particle size (i.e. a few tens of $\mu \mathrm{m}$ ) is usually negligible, the expected signal width value is $\sim 1 \mathrm{~ms}$ (millisecond) for the case of $5 \mathrm{~m} \mathrm{~s}^{-1}$ flow speed. Note that selected, high-quality particle signal width data (without particle overlapping) are only useful when the data are to be used to infer the flow speed values.

Finally, the latest version of CPS also monitors the direct current (DC) component for the detector no. 1 output, which represents any fixed light sources other than the particle scattering component. The DC component includes stray sunlight and scattered (source or sun-) light from any dew and ice on the lenses and from the wall of the detection area. Therefore, high DC values during the daytime indicate potential contamination by stray sunlight.

The temperature dependence of the CPS laser device and detectors was evaluated in a laboratory chamber using a CPS and changing the temperature from +25 to $-30^{\circ} \mathrm{C}$. Note that during the actual flights (e.g. going through the cold tropical tropopause down to $-90^{\circ} \mathrm{C}$ ), the laser device and the detectors are kept relatively warm thanks to the Styrofoam flight box and heat from the CPS circuit board; for example, during a flight the temperature in the flight box was $-25^{\circ} \mathrm{C}$ when the air temperature was $-70^{\circ} \mathrm{C}$. The chamber result was that the detector output changed less than $2 \%$ in the temperature range from +25 to $-30^{\circ} \mathrm{C}$.

The above description of the CPS is broadly applicable also to the pollen sensor PS2 from which the CPS was developed. The major exception is that for the PS2, the two detectors are placed at angles of 60 and $-60^{\circ}$ (the latter located below the light source) with respect to the source-light direction. The configuration of the PS2 gives symmetric geometry for the two detectors but was found to cause particle contamination of the lower-side detector in cloud layers. Therefore, we modified the configuration to that shown in Fig. 1. In Sect. 3.1 we will show the results from a simultaneous flight of a CPS with the PS2 configuration ("PS2 type") and a CPS with the configuration shown in Fig. 1. Other major modifications with respect to the PS2 included (1) the removal of a fan and the use of balloon ascent-descent to introduce the air into the detection area, (2) the installation of a small heater near the light source to reduce icing, and (3) the installation of slits in front of the laser diode and the two detectors 


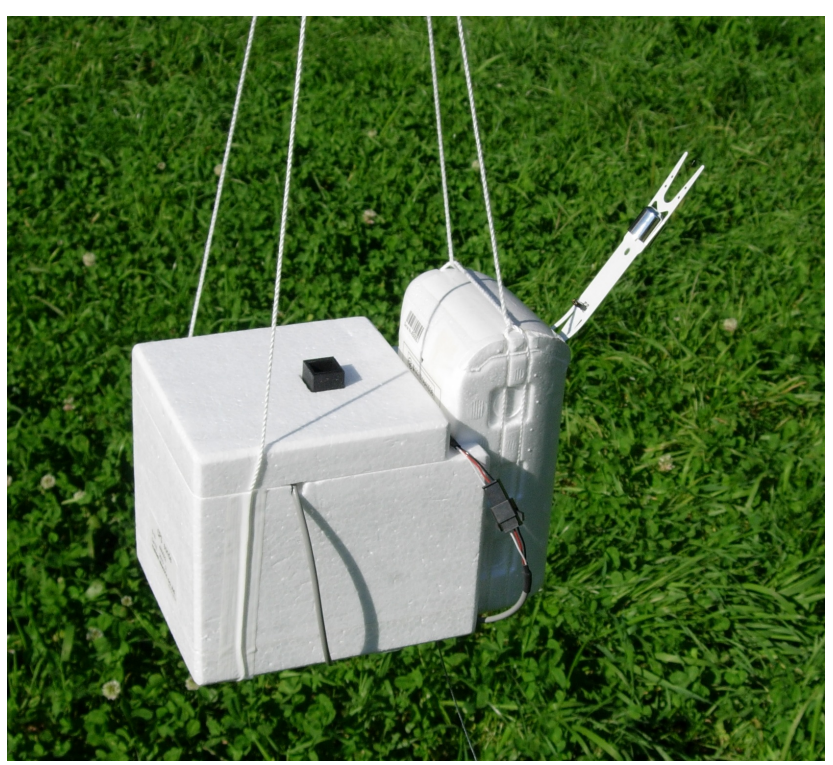

Figure 2. Photograph of the latest version CPS within its flight package (with a black inlet duct on top) connected to the Meisei RS-11G radiosonde (with the temperature and $\mathrm{RH}$ sensor boom). The three 3-V lithium batteries and the interface board are placed within the CPS flight package.

to narrow the detection area and thus to increase the upper limit of the count number. Finally, the air inlet at the top of the latest version CPS extends $1.0 \mathrm{~cm}$ above the Styrofoam flight package surface to avoid counting particles detached from the package surface. For daytime soundings, additional longer air ducts were attached both at the top and the bottom to reduce contamination by stray sunlight. The dimension of the flight package is $\sim 11.5 \mathrm{~cm} \times 14 \mathrm{~cm} \times 12 \mathrm{~cm}$ (Fig. 2), and the mass is $\sim 200 \mathrm{~g}$ including the package and the three $3-\mathrm{V}$ lithium batteries (CR123).

\subsection{Interfacing with the Meisei radiosondes}

The interface board developed for the CPS is capable of counting up to 1000 particles per second and providing $I_{55}$, $I_{125 \mathrm{p}}$, and the signal width values for up to 1000 particles. However, the downlink from the Meisei radiosondes to the

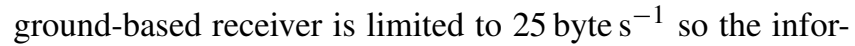
mation needs to be compressed. (Some radiosondes from other manufacturers have greater downlink rate, and it is technically possible to develop an interface board for these radiosondes.) The latest version CPS provides the following data every second: (i) the number of particles counted per second; (ii) values of $I_{55}, I_{125 \mathrm{p}}$, and signal width for the first six particles coming into the instrument for each second; and (iii) the DC component for the detector no. 1 output. The CPS can be connected to a Meisei RS-06G radiosonde (Nash et al., 2011) or to its upgraded version, the Meisei RS-11G radiosonde. Figure 2 shows a photograph of the latest version
CPS within the flight package connected with the Meisei RS$11 \mathrm{G}$ radiosonde.

\subsection{The number concentration measured by the CPS}

The primary measurement of the CPS is the number of particles counted per second. If the flow speed within the detection area of the sensor is estimated or measured, the number per second can be converted to number concentration. The flow speed within an inlet duct is primarily determined by the balloon ascent rate $\left(\sim 5-6 \mathrm{~m} \mathrm{~s}^{-1}\right)$, with additional flow of within about $\pm 2 \mathrm{~m} \mathrm{~s}^{-1}$ due to the payload pendulum motions (depending on the length of the main string, payload configuration, and altitude), but may also depend on the shape and the cross section of the duct and the ambient air density. At Moriya $\left(36^{\circ} \mathrm{N}, 140^{\circ} \mathrm{E}\right)$, Japan, at 17:11:47 LT (at dusk) on 23 November 2012, we launched a CPS with two hot-wire anemometers in an extended straight duct attached below the CPS (Appendix B). These anemometers had been calibrated by laboratory experiments under low-temperature and low-pressure conditions before the launch and its uncertainty is considered to be $\pm 1 \mathrm{~m} \mathrm{~s}^{-1}(k=2)$. We found that from the surface up to $\sim 10 \mathrm{~km}$, the balloon ascent rate was 5-6 $\mathrm{m} \mathrm{s}^{-1}$, flow speed measured by the anemometer no. 1 was $4-5 \mathrm{~m} \mathrm{~s}^{-1}$, and flow speed for no. 2 was $3-4 \mathrm{~m} \mathrm{~s}^{-1}$, with increasing discrepancy between nos. 1 and 2 at higher altitudes. See Appendix B for the details of this sounding. We also made another test flight at Moriya at 17:30 LT on 12 October 2011 (Sect. 3.2.4 of Sugidachi, 2014) where the flow speed within four $\sim 30 \mathrm{~cm}$ length straight ducts with different cross sections (i.e. three tubes with 2,3 , and $15 \mathrm{~cm} \mathrm{di-}$ ameter, and a duct with $2 \mathrm{~cm} \times 2 \mathrm{~cm}$ inlet and $3 \mathrm{~cm} \times 3 \mathrm{~cm}$ outlet) was measured using hot-wire anemometers during a balloon ascent. We found that the flow speed in these ducts roughly agrees with the balloon ascent rate $\left(\sim 5-7 \mathrm{~m} \mathrm{~s}^{-1}\right)$ within $\pm 1-3 \mathrm{~m} \mathrm{~s}^{-1}$ in the troposphere. In summary, the assumption that the flow speed within the detection area is equal to the balloon ascent rate in the troposphere can be used as a first approximation but may cause uncertainty of a factor of $\sim 2$ in the estimated number concentration. (Note that the flow speed would be much smaller if longer, nonstraight air ducts are attached both at the top and the bottom, e.g. for daytime soundings to avoid contamination by stray sunlight.) In this paper, for simplicity, we assume a constant flow speed of $5 \mathrm{~m} \mathrm{~s}^{-1}$.

As described in the previous section, the maximum number of particles (i.e. 1000) counted per second is determined by the interface board. However, the actual maximum number that can be correctly counted is thought to be much smaller because with such a high number concentration, particle signal overlap and multiple light scattering would occur. The following is a rough estimate of the actual limit for the number concentration and the number of particles counted per second. As described above, the volume of the detection area is non-zero and estimated as $\sim 0.5 \mathrm{~cm}^{3}$. Therefore, 
when the particle number concentration is close to or more than $2 \mathrm{~cm}^{-3}$, more than one particle would exist simultaneously in the detection area, resulting in particle overlap and multiple scattering and thus a counting loss. Therefore, the CPS can correctly measure number concentrations less than $\sim 2 \mathrm{~cm}^{-3}$ (i.e. $2 \times 10^{3} \mathrm{~L}^{-1}$ ). Assuming that the flow speed is $5 \mathrm{~m} \mathrm{~s}^{-1}$, and the cross section of the detection area is $1 \mathrm{~cm}^{2}$, the number concentration of $\sim 2 \mathrm{~cm}^{-3}$ corresponds to $\sim 1000$ particles $\mathrm{s}^{-1}$. Furthermore, the particle signal width data can also be used to check whether particle signal overlap is occurring. As discussed in Sect. 2.1, the flow speed of $5 \mathrm{~m} \mathrm{~s}^{-1}$ corresponds to a signal width of $\sim 1 \mathrm{~ms}$ for a single particle. If the signal width value is close to or greater than $\sim 1 \mathrm{~ms}$, it is highly possible that signal overlap and counting loss are occurring. In actual flights, as will be shown in Sect. 3, dense cloud layers often give particle counts of $\sim 100 \mathrm{~s}^{-1}$ (or even less) and signal width of $1-5 \mathrm{~ms}$; what happens here is that, due to signal overlap, the number of particles is reduced to $\sim 100 \mathrm{~s}^{-1}$. When the signal width is greater than $1 \mathrm{~ms}$, a partial correction of the number of particles might be possible by using a factor $f=$ (signal width in $\mathrm{ms}) /(1 \mathrm{~ms})$ and by considering the dimensions of the detection area (i.e. $\sim 1 \mathrm{~cm} \times 1 \mathrm{~cm}$ in the horizontal and $0.5 \mathrm{~cm}$ in the vertical) as $N_{\text {cor }}=N_{\text {org }} \times 2 f \times 2 f \times f=N_{\text {org }} \times 4 f^{3}$, where $N_{\text {cor }}$ and $N_{\text {org }}$ are the corrected and original numbers of particles, respectively. For example, when the signal width value is $5 \mathrm{~ms}$, at least five particles would have been in line in the vertical in the detection area. The factor " $f$ " is introduced for this reason. Furthermore, if it is assumed that particles are homogeneously distributed in the detection area, the same argument would hold in the horizontal. The factor of 2 for the possible horizontal overlapping comes from the fact that the detection area is twice as long in the horizontal as the vertical. Although consideration of the statistical distribution of particles in the detection area may be needed for more accurate correction, this simple approach should give a first, rough approximation. Note that if we use the balloon ascent rate as the flow speed (see Appendix B), this correction may give an upper-bound estimate. See Appendix C for other flow speed values and for the contribution of the uncertainty in flow speed to the uncertainty in $N_{\text {cor }}$. It is currently not possible to quantify the uncertainty of number concentration when the above correction is applied (i.e. when it is greater than $\sim 2 \mathrm{~cm}^{-3}$ ). Intercomparisons with other, wellcharacterized instruments are necessary for the uncertainty quantification.

\subsection{Relative humidity calculations}

Before discussing the CPS results, some notes are given on the $\mathrm{RH}$ plots in the following figures. The $\mathrm{RH}$ values reported from radiosondes are, by convention, always those with respect to liquid water even at air temperatures below $0{ }^{\circ} \mathrm{C}$. The ice saturation $\mathrm{RH}$ values below $0^{\circ} \mathrm{C}$ are always smaller than $100 \%$, as shown by the dashed curve in the following $\mathrm{RH}$ figures. When the reported RH value exceeds the ice saturation RH value at the same location, it is possible that cloud particles were present. For the tropical soundings shown below (Sect. 3.3 and 3.4), we will also show the RH profiles obtained from the cryogenic frost-point hygrometer (CFH) (Vömel et al., 2007, 2016) flown on the same balloon (with the radiosonde temperature measurements). The CFH RH values in the tropical upper troposphere are considered to be much more reliable than the radiosonde $\mathrm{RH}$ values, because radiosonde RH sensors suffer seriously from time-lag errors in such high-altitude and cold-temperature regions (e.g. Nash et al., 2011). See Fujiwara et al. (2003) for the formula of the RH with respect to liquid water and of the ice saturation RH. In this study, we used the water vapour pressure equations developed by Hyland and Wexler (1983), as shown in Murphy and Koop (2005).

\section{Results from test flights}

Twenty-five test flights of the CPS with the Meisei RS-06G or RS- $11 \mathrm{G}$ radiosonde were made during the period between November 2012 and March 2015. There were 11 flights at Moriya $\left(36^{\circ} \mathrm{N}, 140^{\circ} \mathrm{E}\right)$, Japan; two at Tateno $\left(36^{\circ} \mathrm{N}\right.$, $\left.140^{\circ} \mathrm{E}\right)$, Japan; three at Palau $\left(7^{\circ} \mathrm{N}, 134^{\circ} \mathrm{E}\right)$; and nine at Biak $\left(1^{\circ} \mathrm{S}, 136^{\circ} \mathrm{E}\right)$, Indonesia. For the first two flights, at Moriya, we used a version of CPS with the same instrumental configuration as for the PS2 (the PS2 type CPS described in Sect. 2.1) and found that the lower detector part became highly contaminated after passing through supercooled cloud layers. We then developed the version with the configuration shown in Fig. 1 to minimize the particle contamination effects. We also tested some other versions with minor variations in the instrumental configuration to try to improve the upper limit of the number of particles. Among the 25 flights, two flights with two sensors on a single balloon were made at Moriya to compare different configurations (see Sect. 3.1 for the results from one of the flights). We also found that daytime soundings often give noisier CPS output data due to contamination by stray sunlight and that soundings at dusk and at night give CPS data of much higher quality. In this section, we show the results from four balloon flights, two from Moriya (a midlatitude site) and two from Biak (a tropical site), and discuss the capabilities and limitations of the CPS. It is noted here that the uncertainty of the RH measurements of the Meisei radiosondes is $\pm 7 \% \mathrm{RH}$.

\subsection{Simultaneous flights of two different types of CPS}

At Moriya, at 18:07 LT on 18 March 2013, we launched two CPSs simultaneously on a single $600 \mathrm{~g}$ balloon, one with the configuration shown in Fig. 1 and the other with the PS2 configuration (PS2 type; see Sect. 2.1), to compare the two types and to confirm the general performance of the CPS. The RS-06G radiosondes were used to downlink the data 

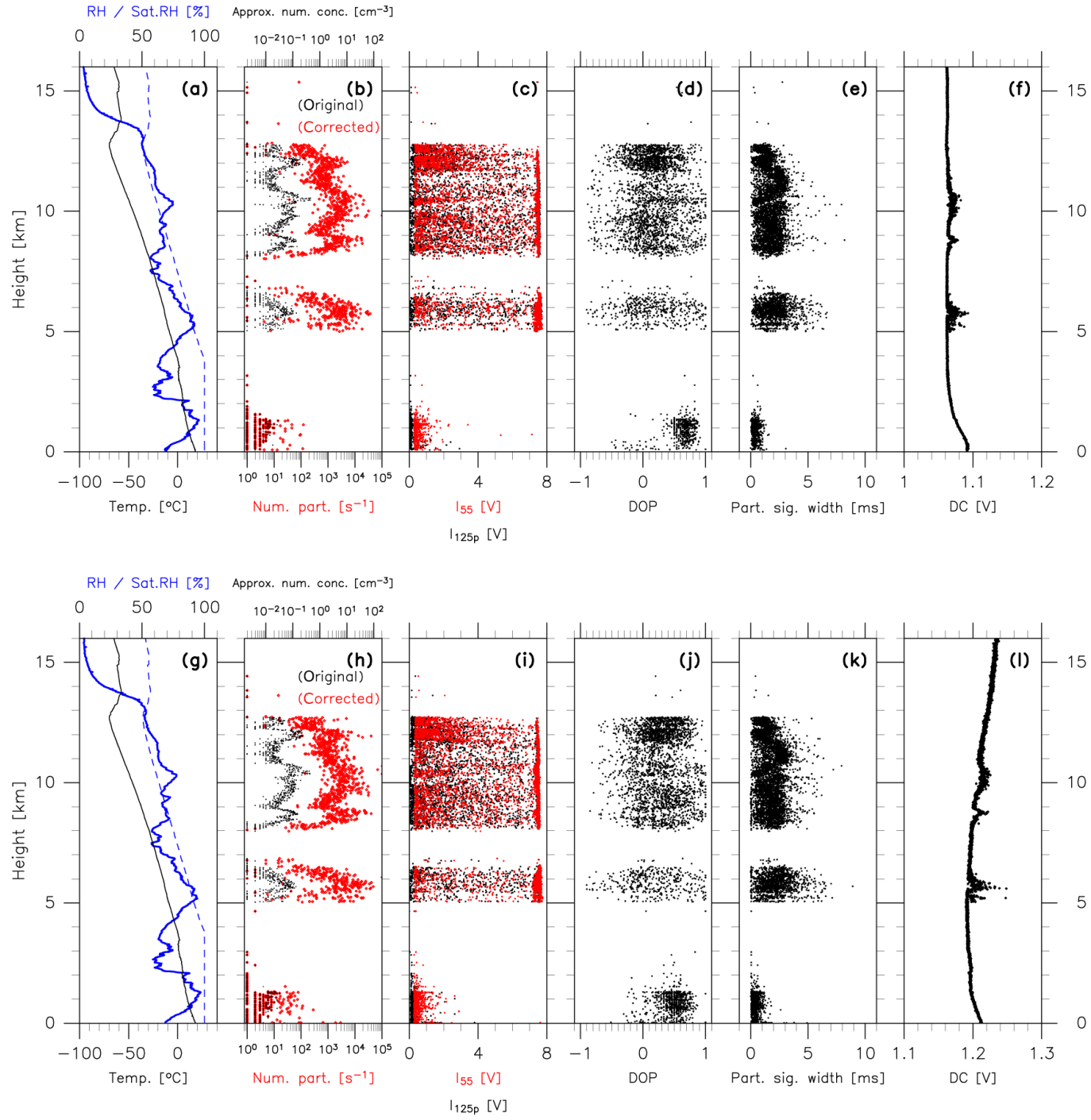

Figure 3. Results from a flight of two CPSs on the same $600 \mathrm{~g}$ balloon at Moriya, Japan, launched at 18:07 LT on 18 March 2013. Top panels (a-f) show data taken from the CPS with the configuration shown in Fig. 1 and bottom panels (g-l) from the PS2-type CPS (see the last paragraph of Sect. 2.1). Vertical profiles are shown of (a, g) temperature (black), RH (blue solid), and ice saturation RH (dashed blue) from the RS-06G radiosondes; (b, h) number of particles counted per second (and number concentration assuming $5 \mathrm{~m} \mathrm{~s}^{-1}$ flow speed), original in black and corrected (see text for details) in red; (c, i) particle output voltages $I_{55}$ (red) and $I_{125 p}$ (black); (d, j) the degree of polarization (DOP) (not calculated when $I_{55}$ is greater than $7 \mathrm{~V}$; see text); (e, k) particle signal width in ms; and (f, l) the DC component from the detector no. 1 output.

for both sensors and to measure the profiles of temperature, $\mathrm{RH}$, height, pressure, and horizontal winds. At the time of launch, the site was located at the southeastern edge of a low-pressure system, though there was no rainfall observed. As described below, there was a local, surface mineral dust event on the day of flight due to strong surface wind in association with the low-pressure system. Satellite cloud images show that the site was covered by a wide stratus cloud band associated with the low-pressure system.

Figure 3 shows the vertical profiles of radiosonde and CPS variables obtained from this flight. In the RH panel, the ice saturation RH curve (Sect. 2.4) is also shown. In the middle to upper troposphere, this curve, rather than $100 \%$, indicates the reference to saturation and cloud formation. In the panel for number of particles, both original and "corrected" values (the latter is $N_{\text {org }} \times 4 f^{3}$ when the particle signal width value (the maximum among up to six values per second) is greater than $1 \mathrm{~ms}$ and $N_{\text {org }}$ when the width is equal to or smaller than $1 \mathrm{~ms}$; see the discussion in Sect. 2.3 and Appendix C for the uncertainty of this correction method) are plotted. This panel also shows a conversion to approximate number concentration values by assuming a constant flow speed of $5 \mathrm{~m} \mathrm{~s}^{-1}$ (see 


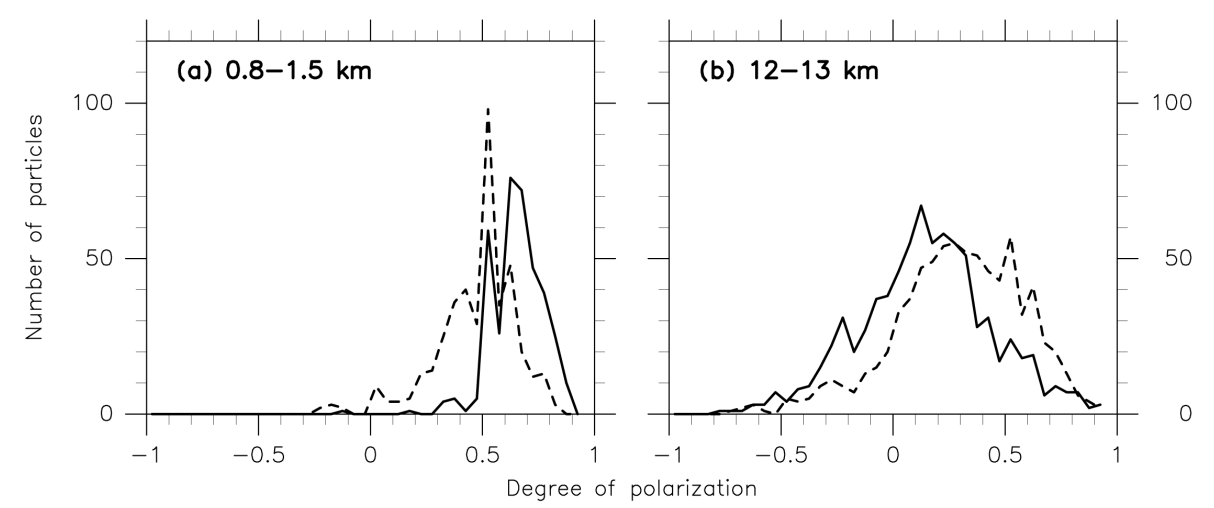

Figure 4. Frequency distributions of the degree of polarization (DOP) in 0.05 bins from the results shown in Fig. 3 at (a) $0.8-1.5 \mathrm{~km}$ (water clouds) and for (b) $12-13 \mathrm{~km}$ (ice clouds). For both panels, the solid curves are for the CPS (with the configuration in Fig. 1), while the dashed curves are for the PS2-type CPS (last paragraph of Sect. 2.1).

Appendix $\mathrm{C}$ for other flow speed values), with the cross section of detection area as $1 \mathrm{~cm}^{2}$ (e.g. $1000 \mathrm{~s}^{-1}$ corresponds to $\left.2 \mathrm{~cm}^{-3}\right)$. The $I_{55}, I_{125 \mathrm{p}}$, DOP, and particle signal width data are those for the first six particles for each second, even when the number of particles per second is much greater than six (see Sect. 2.2 for the reason and for possible future improvements). Also, in this paper, DOP is not calculated when the corresponding $I_{55}$ is greater than $7 \mathrm{~V}$; this is because in the ice or mixed-phase cloud regions, these cases create a strong peak around zero in the DOP frequency distribution. (Note that there was no such case in the water cloud regions in the results shown in this paper; thus, there is no contradiction to the statement in Sect. 2.1 about the phase characterization using DOP for large particles.) Finally, the DC component for the detector no. 1 output is also shown for this flight. Because this flight was made at dusk, there was virtually no contamination by stray sunlight. The average, background DC value (i.e. 1.06-1.1 for the latest version CPS and 1.2-1.24 for PS2 type for this flight) differs for individual CPSs due to, for example, different conditions of the wall of the detection area. As can be seen for this flight (at 5-6 km, around $8.8 \mathrm{~km}$, and at $9.5-11 \mathrm{~km}$ ), DC data can also show signals of this magnitude in dense cloud layers, where very strong particle overlap and multiple scattering occur so that the detector no. 1 output tends to be enhanced continuously (rather than intermittently). Thus, consideration of DC data might also be required for the full counting-loss correction. Under the influence of stray sunlight, DC data would show much greater values (e.g. more than $2 \mathrm{~V}$ ).

In Fig. 3 the two CPSs show very similar cloud profiles. For example, the difference in the original number-ofparticle values from the two CPSs is mostly within $\pm 10 \mathrm{~s}^{-1}$ (with several exceptions for the cloud layers above $5 \mathrm{~km}$ ). The characteristics of each cloud layer are as follows. Between $\sim 0.8$ and $\sim 1.5 \mathrm{~km}$, there is a cloud layer of up to $\sim 1$ to $10^{2} \mathrm{~s}^{-1}$ (corrected values) (corresponding to $\sim 2 \times 10^{-3}$ to $2 \times 10^{-1} \mathrm{~cm}^{-3}$ assuming a flow speed of $5 \mathrm{~m} \mathrm{~s}^{-1}$ ), with high but unsaturated RH values. The $I_{55}$ values are generally less than $1 \mathrm{~V}$, implying that the particles are very small (less than $\sim 20 \mu \mathrm{m}$ ). The DOP values are mainly in the range $0.5-1$ (see also Fig. 4, showing the DOP frequency distribution for $0.8-1.5 \mathrm{~km}$ ), indicating that the particles are quasi-spherical and thus water droplets. This is also supported by the fact that the air temperature is higher than $0^{\circ} \mathrm{C}$. The signal width values are generally less than $1 \mathrm{~ms}$, indicating that particle overlap and counting loss are mostly not occurring. Between 5 and $7 \mathrm{~km}$, there is another cloud layer of up to $\sim 10^{2}$ to $10^{4} \mathrm{~s}^{-1}$ (corrected values) (corresponding to $\sim 2 \times 10^{-1}$ to $20 \mathrm{~cm}^{-3}$ assuming a flow speed of $5 \mathrm{~m} \mathrm{~s}^{-1}$ ), with high RH values, some of which exceed the ice saturation $\mathrm{RH}$ values. The $I_{55}$ values range from $\sim 0$ to $\sim 7.5 \mathrm{~V}$, with many particles showing $\sim 7.5 \mathrm{~V}$, implying the existence of very large particles $(>80 \mu \mathrm{m})$ and/or the occurrence of particle overlap. The DOP values are distributed widely within \pm 1 , indicating that the particles are nonspherical and thus ice particles. This is also supported by the air temperature ranging from -10 to $-30^{\circ} \mathrm{C}$. The signal width values are mostly in the range $0-3 \mathrm{~ms}$ and sometimes reach $\sim 5 \mathrm{~ms}$ (i.e. often exceed $1 \mathrm{~ms}$ ), indicating that particle overlap and counting loss have occurred. Thus, the number-of-particle values have been corrected. From $8 \mathrm{~km}$ to the tropopause $(\sim 12.8 \mathrm{~km})$, there is another group of cloud layers with varying numbers of particles. There are three distinct peaks in (corrected) number of particles $\left(\sim 2 \times 10^{3} \mathrm{~s}^{-1}\right.$ at $8.7 \mathrm{~km}$ and around $10.5 \mathrm{~km}$, and $\sim 10^{3} \mathrm{~s}^{-1}$ at $12 \mathrm{~km}$ ), with near-saturated or even supersaturated RH values. The characteristics in $I_{55}$, DOP, and signal width are similar to those for the $5-7 \mathrm{~km}$ cloud layer. Thus, particle overlap and counting loss have also occurred for these upper tropospheric cloud layers, and the numberof-particle values have been corrected. These layers are also ice clouds, as indicated by the DOP distribution and air temperature values.

As noted in the beginning of this section, there was a local dust event on 18 March 2013, which is supported by 


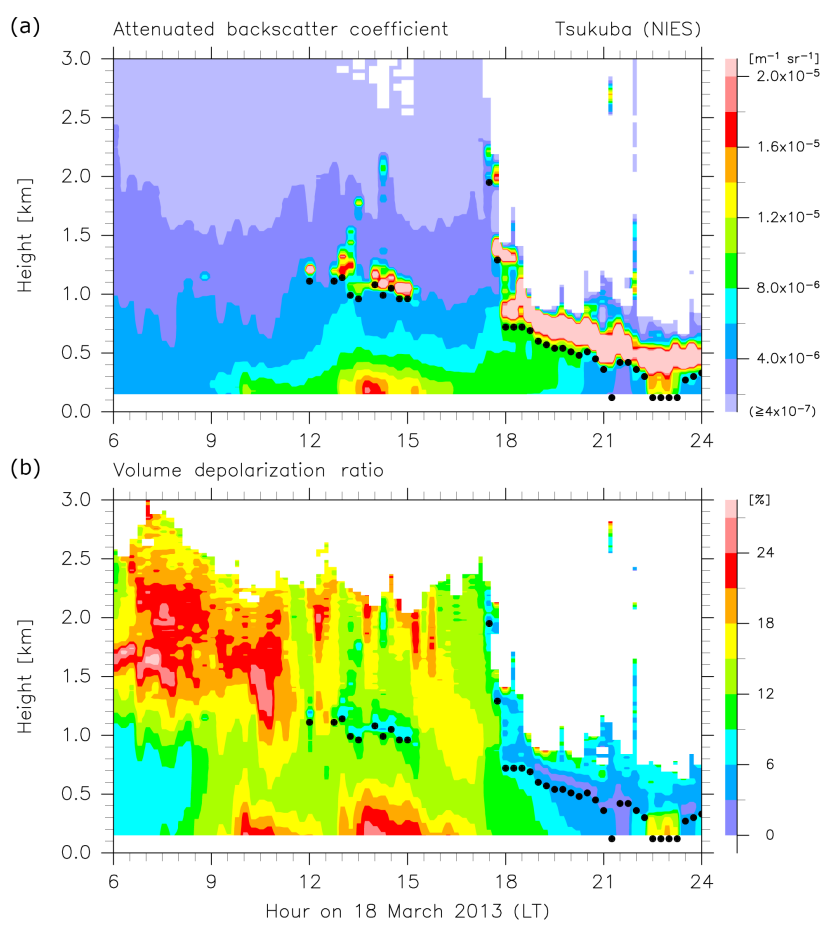

Figure 5. Time-height distributions of attenuated backscatter coefficient at $532 \mathrm{~nm}$ (top) and volume depolarization ratio at $532 \mathrm{~nm}$ (bottom) measured with a lidar system at Tsukuba $\left(36.05^{\circ} \mathrm{N}\right.$, $140.12^{\circ}$ E) between 06:00 and 24:00 LT on 18 March 2013. See Shimizu et al. (2004) for the definition of the depolarization ratio. Small depolarization ratios (e.g. $<5 \%$ ) indicate that particles are spherical. Temporal resolution is $15 \mathrm{~min}$, and vertical resolution is $30 \mathrm{~m}$, with the lowest $120 \mathrm{~m}$ portion of the data not shown because of large uncertainty. For the depolarization ratio plot, data points whose $532 \mathrm{~nm}$ backscatter coefficient is $<1.0 \times 10^{-6} \mathrm{~m}^{-1} \mathrm{sr}^{-1}$ are not shown. Also shown with dots in both panels are the cloud base location estimated from the $1064 \mathrm{~nm}$ lidar measurements (i.e. the lowest level where vertical gradient of $1064 \mathrm{~nm}$ attenuated backscatter coefficient exceeds $1.2 \times 10^{-6} \mathrm{~m}^{-1} \mathrm{sr}^{-1}$ per $60 \mathrm{~m}$ and the maximum attenuated backscatter coefficient in the cloud layer must exceed $2.0 \times 10^{-5} \mathrm{~m}^{-1} \mathrm{sr}^{-1}$, with apparent cloud top where attenuated backscatter coefficient value becomes equal to that at the cloud base).

surface observations of enhanced suspended particulate matter (SPM; particles smaller than $10 \mu \mathrm{m})$ at five sites located $3-14 \mathrm{~km}$ from the launch site (data obtained from the environmental database of the National Institute for Environmental Studies (NIES)) and by Sugimoto et al. (2016) who discussed this event based on depolarization lidar and surface particle $\left(\mathrm{PM}_{2.5}\right.$ and $\left.\mathrm{PM}_{10}\right)$ measurements at Tsukuba $\left(36.05^{\circ} \mathrm{N}, 140.12^{\circ} \mathrm{E}\right)$, which is located $\sim 16 \mathrm{~km}$ from the launch site. These dust particles are mineral dust blown up by the strong wind from unplanted fields in this area. Figure 5 shows the results from the depolarization lidar measurements at Tsukuba between 06:00 and 24:00 LT on 18 March 2013. This lidar system uses 532 and $1064 \mathrm{~nm}$ laser light, with the depolarization measurement capability at $532 \mathrm{~nm}$ (Shimizu et al., 2004; Sugimoto et al., 2008). It takes $15 \mathrm{~min}$ for one cycle of the measurement, including 5 min laser light emission and $10 \mathrm{~min}$ temporary pause. The vertical resolution of the data is $30 \mathrm{~m}$. Figure 5 shows that the local dust event, confined up to $\sim 0.5 \mathrm{~km}$, started around 09:00 LT and ended around 19:00-20:00 LT. The dust particles have depolarization ratios of $\sim 15-30 \%$. In contrast, at 18:00 LT, low-level clouds appeared whose base was estimated to be located at $0.72 \mathrm{~km}$, and the cloud base descended gradually afterwards. These clouds are characterized by large backscatter coefficients (greater than $1 \times 10^{-5} \mathrm{~m}^{-1} \mathrm{sr}^{-1}$ ) and small depolarization ratios (less than 10\%). The two CPSs were launched at Moriya at 18:07:44 LT. Therefore, these CPSs should have encountered mineral dust particles (which might have been somewhat wet) up to $\sim 0.5 \mathrm{~km}$ and water cloud particles above $\sim 0.7 \mathrm{~km}$. In fact, the CPS with the configuration in Fig. 1, which was placed outside at the surface from $\sim 300 \mathrm{~s}$ before the launch, detected particles at the surface and up to $\sim 0.5 \mathrm{~km}$ whose DOP is distributed widely between -1 and +1 . Above $\sim 0.5 \mathrm{~km}$, the DOP became much more confined to $\sim 0.5-0.9$. The former group of particles are considered to be the mineral dust particles, and the latter group of particles are mostly spherical particles, i.e. mostly water cloud particles. Figure 4 compares the DOP frequency distributions for two cloud regions, one at $0.8-1.5 \mathrm{~km}$ (i.e. water clouds since air temperatures are higher than $0{ }^{\circ} \mathrm{C}$ ) and the other at $12-13 \mathrm{~km}$ (i.e. ice clouds as air temperatures are lower than $-65^{\circ} \mathrm{C}$ ) and between the two CPSs with different configurations. Figure 4 shows that for water droplets, the DOP values only lie in the positive region, being mostly within $0.5-1$, particularly for the CPS with the configuration in Fig. 1. In contrast, for ice-cloud particles, the DOP is distributed widely within \pm 1 , with a peak around zero, particularly for the CPS with the configuration in Fig. 1. It is noted that for water droplets, DOP does not necessarily become exactly unity as $I_{125 p}$ does not necessarily become exactly zero. The latter is in part because there might be several azimuthal and zenith angles for the scattering water surface depending on the exact location of a water particle in the detection area. The actual DOP distribution for water droplets also depends on the factory calibration and thus differs slightly for different CPS instruments as shown in this and the following cases. However, as has been shown in this case, it is very different from that for ice particles.

In summary, the fact that the two CPSs with different configurations show very similar cloud profiles suggests the robustness of this technique for cloud particle measurements. Because some other earlier flights showed that the PS2-type configuration sometimes results in particle contamination to the lower-side detector, we have developed the version with the configuration shown in Fig. 1. The following three cases are all observed using the CPS with the configuration in Fig. 1. 


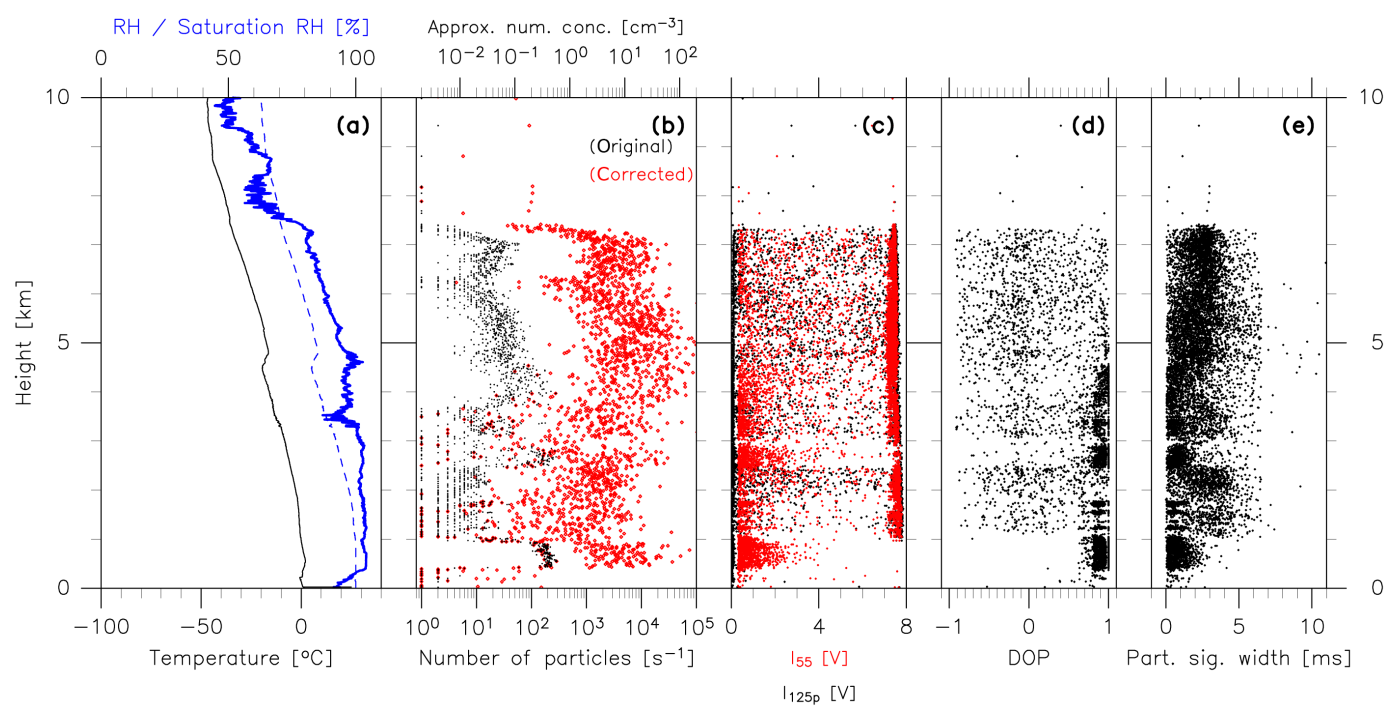

Figure 6. Results from a CPS flight at Moriya, Japan, launched at 17:30 LT on 21 January 2015. Vertical profiles are shown of (a) temperature (black), RH (blue solid), and ice saturation RH (dashed blue) from the RS-11G radiosonde; (b) number of particles counted per second (and number concentration assuming $5 \mathrm{~m} \mathrm{~s}^{-1}$ flow speed), original in black and corrected (see Sects. 2.3 and 3.1) in red; (c) particle output voltages $I_{55}$ (red) and $I_{125 p}$ (black); (d) the degree of polarization (DOP) (not calculated when $I_{55}$ is greater than $7 \mathrm{~V}$; see Sect. 3.1 ); and (e) particle signal width in $\mathrm{ms}$.

\subsection{Midlatitude precipitating clouds}

At Moriya, at 17:30 LT on 21 January 2015, the first commercial version of the CPS was launched with the RS-11G radiosonde to confirm its general performance under precipitating nimbostratus-stratocumulus conditions at midlatitudes. At the launch, low-level thick clouds were visually observed from the ground, and it started to rain lightly. A low-pressure system was developing to the southwest.

Figure 6 shows the vertical profiles of temperature, $\mathrm{RH}$, and the CPS output data (same as in Fig. 3, but without DC data). The RH profile suggests that clouds covered basically throughout the troposphere, except for the first few hundred metres from the surface. It is suspected that the RH measurements may be $\sim 10 \% \mathrm{RH}$ biased wet at least from $\sim 5$ to $\sim 7.5 \mathrm{~km}$ (i.e. the pure ice-cloud region, as will be discussed below), but the vertical structure of the atmosphere is well captured. The CPS detected cloud particles basically throughout the troposphere from $\sim 0.4$ up to $\sim 7.5 \mathrm{~km}$, and no particles above this level, generally consistent with the $\mathrm{RH}$ measurements. The profile of the corrected number of particles has less vertical structures compared with the original one, indicating vales of $10^{2}$ to $10^{4} \mathrm{~s}^{-1}\left(\sim 2 \times 10^{-1}\right.$ to $20 \mathrm{~cm}^{-3}$ ). Above $1 \mathrm{~km}$, the $I_{55}$ values of many of the particles are $\sim 7.5 \mathrm{~V}$, implying the existence of very large particles and/or particle overlap. It is these particles that give nearzero DOP values (as both $I_{55}$ and $I_{125 p}$ are $\sim 7.5 \mathrm{~V}$ ). Such particles are excluded from the analysis of DOP frequency distributions shown in Fig. 7 (note again that this does not influence the water cloud detection). Interestingly, DOP data show a complex cloud-phase distribution in the vertical. In the region up to $\sim 1 \mathrm{~km}$ where DOP values are mostly $0.8-$ 1.0 , water clouds existed. From $\sim 1$ up to $\sim 4.5 \mathrm{~km}$ (about $-20^{\circ} \mathrm{C}$, capped by a distinct temperature inversion), DOP values show two groups, one with $0.8-1.0$ and the other ranging widely within \pm 1.0 (Fig. 6d). See Fig. $7 b$ for the DOP frequency distribution at $2.5-4.5 \mathrm{~km}$ (this altitude region is taken as an example). This suggests the existence of mixedphase clouds where water and ice clouds co-existed. Above $\sim 5 \mathrm{~km}$, the DOP distribution is typical of ice clouds. Note that for this particular sounding, the DOP frequency distribution for water cloud particles is rather atypical, having its peak at $0.9-1$ (Fig. 7a and b). Finally, the signal width values are $0-2 \mathrm{~ms}$ from the surface to $1 \mathrm{~km}$ and $0-5 \mathrm{~ms}$ above $1 \mathrm{~km}$ (i.e. often exceeding $1 \mathrm{~ms}$ ), indicating that particle overlap and counting loss have occurred; thus, the correction has been made for the number-of-particle values.

In summary, this flight confirmed that the CPS can also be operated within midlatitude precipitating systems. This is also a good example showing the CPS's ability to detect mixed-phase clouds as well as pure water clouds and pure ice clouds.

\subsection{Tropical mid- and upper tropospheric thick cloud layers}

At Biak, Indonesia, at 18:00 LT on 23 February 2015, a CPS interfaced with an RS-11G and a CFH (Sect. 2.4) and ozonesonde interfaced with an RS-06G were flown on a single balloon during an observation campaign by the Soundings of Ozone and Water in the Equatorial Region (SOWER) 

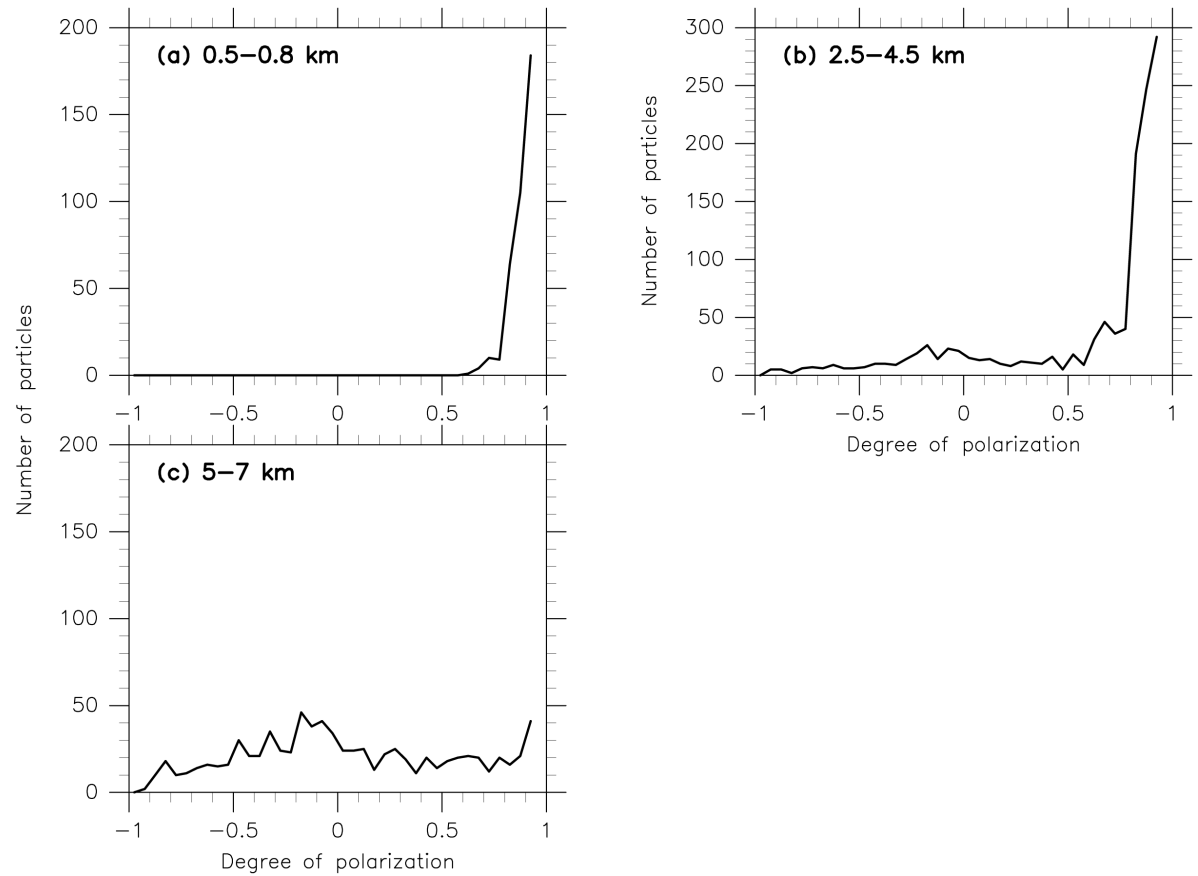

Figure 7. Frequency distribution of the degree of polarization (DOP) in 0.05 bins from the results shown in Fig. 6 at (a) $0.5-0.8 \mathrm{~km}$ (water clouds), (b) $2.5-4.5 \mathrm{~km}$ (mixed-phase clouds), and (c) $5-7 \mathrm{~km}$ (ice clouds). Note that particles with $I_{55}$ values greater than $7.0 \mathrm{~V}$ were excluded from the analysis, as such particles create a very large peak around zero for ice or mixed-phase clouds.

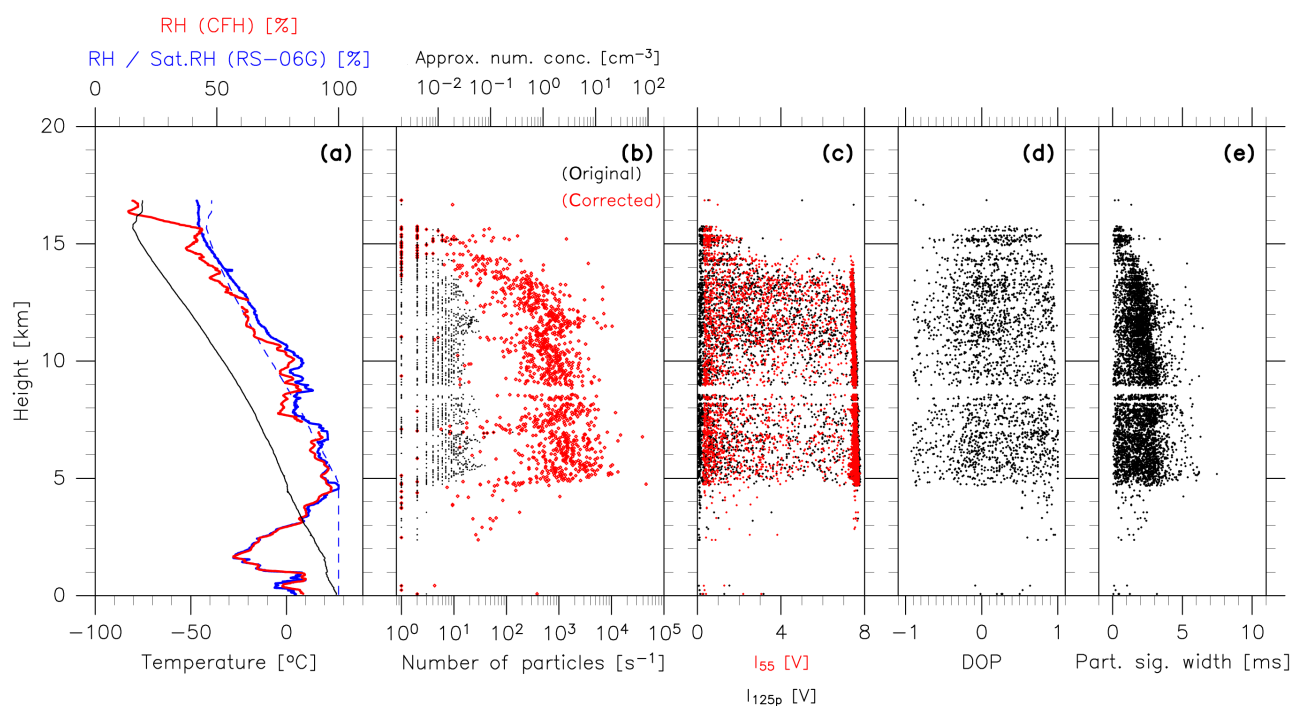

Figure 8. As for Fig. 6, but for the profiles taken at Biak, Indonesia, launched at 18:00 LT on 23 February 2015. In panel (a), data from the $\mathrm{RS}-06 \mathrm{G}$ radiosonde are plotted, and $\mathrm{RH}$ from the $\mathrm{CFH}$ (red) is also shown.

project (e.g. Hasebe et al., 2013). Satellite cloud images show that the Indonesian Maritime Continent and tropical western Pacific were covered with groups of clouds associated with the Madden-Julian Oscillation (e.g. Zhang, 2005), but there was no rainfall at the site at the launch time.

Figure 8 shows the vertical profiles of temperature, $\mathrm{RH}$, and the CPS output data for the flight. Two RH profiles are shown, one taken from the RS-06G and the other calculated from CFH dew-point/frost-point temperature data and RS06G air temperature data (see Sect. 2.4). From the surface to $5 \mathrm{~km}\left(\sim 0{ }^{\circ} \mathrm{C}\right.$ air temperature $)$, both $\mathrm{RH}$ values agree well. Between 5 and $\sim 12 \mathrm{~km}$, detailed structures in the $\mathrm{RH}$ profile correspond well, though the RS-06G RH is $\sim 5 \% \mathrm{RH}$ wetter than the CFH RH. Above $\sim 12 \mathrm{~km}$, the $\mathrm{CFH}$ RH shows 


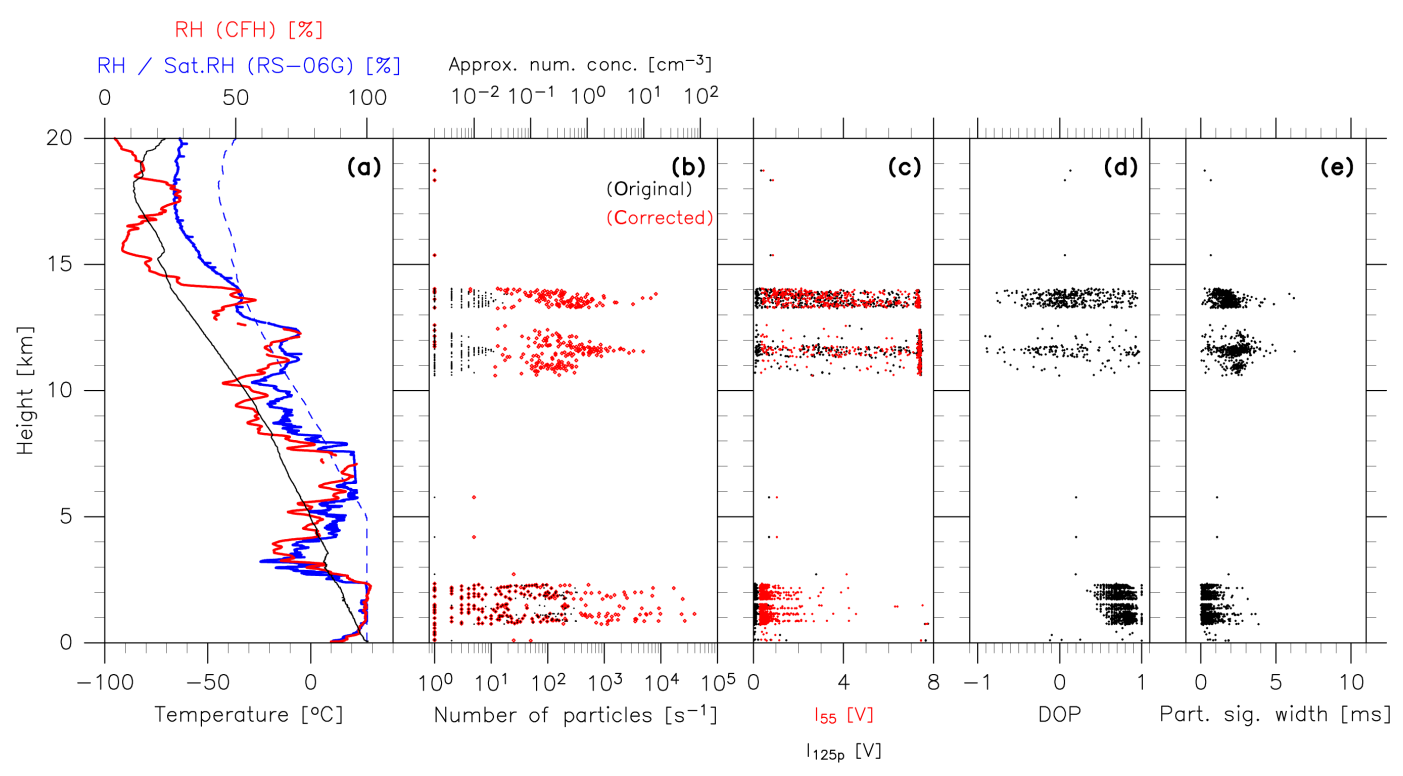

Figure 9. As for Fig. 8, but for the profiles taken at Biak launched at 18:00 LT on 27 February 2015.

layered structures in RH with a sharp drop at the cold-point tropopause at $\sim 15.8 \mathrm{~km}$, while the RS-06G RH shows no such structures with only gradual decrease with height up to the tropopause. The latter is due to the time-lag errors in the radiosonde RH sensors (e.g. Nash et al., 2011) in the upper troposphere and lower stratosphere, with very slow response at very cold temperatures. Thus, in the following discussion, we only refer to the CFH RH profile. The number of particles and the DOP in Fig. 8 show that ice-cloud particles are observed continuously between $\sim 5 \mathrm{~km}$ and the cold-point tropopause. The values of the corrected number of particles are $\sim 10^{2}$ to $5 \times 10^{3} \mathrm{~s}^{-1}$, or $2 \times 10^{-1}$ to $10 \mathrm{~cm}^{-3}$. The signal width values are mostly $0-3 \mathrm{~ms}$, so that particle overlap and counting loss should have occurred; thus, the correction has been made for the number-of-particle values. Note that the CPS measurements were missing at $8.6-9 \mathrm{~km}$ for some reason (probably due to a temporary failure in the CPS board or the interface board or due to the telemetry failure).

In summary, this flight confirms that the commercial version of the CPS works well for ice clouds in the tropical middle and upper troposphere. It also shows that the system works well at cold temperatures down to $-80^{\circ} \mathrm{C}$ (around the tropopause).

\subsection{Tropical upper tropospheric thin cirrus layers}

At Biak, at 18:00 LT on 27 February 2015, another set of a CPS and CFH-ozonesonde was launched during the same SOWER campaign as in Sect. 3.3. There was no rainfall at the site at the launch time. Satellite cloud images show that the site was still covered by groups of clouds similar to those on 23 February. The characteristics of temperature, CFH RH, and ozone above $\sim 14 \mathrm{~km}$ (Fig. 9a, but ozone not shown) are indicative of downward stratospheric air transport in association with a downward-displacement phase of equatorial Kelvin waves (e.g. Fujiwara et al., 2001, 2009). Air was dry and cloud free above $\sim 14 \mathrm{~km}$ for this reason.

Figures 9 and 10 show the results obtained from this flight. Between 0.8 and $2.4 \mathrm{~km}$, the air is saturated with a high number of water cloud particles of 1 to $10^{4} \mathrm{~s}^{-1}$ or $2 \times 10^{-3}$ to $20 \mathrm{~cm}^{-3}$ (corrected values). The signal width values are generally $0-2 \mathrm{~ms}$ with some larger values up to $4 \mathrm{~ms}$. In the middle troposphere at $6-8 \mathrm{~km}, \mathrm{RH}$ data from both the RS-06G and CFH show supersaturation, but the CPS shows zero particle count. There are two ice-cloud layers in the upper troposphere, at 10.5-12.6 and at $13.3-14 \mathrm{~km}$, both with counts of 10 to $10^{3} \mathrm{~s}^{-1}$ or $2 \times 10^{-2}$ to $2 \mathrm{~cm}^{-3}$ (corrected values). The signal width values are $0-5 \mathrm{~ms}$ for both layers, indicating that particle overlap and counting losses have occurred. For both layers, the air is saturated or even slightly supersaturated. It is interesting to note that a high supersaturation layer is located at $11.5-12.5 \mathrm{~km}$ (from the CFH measurements); i.e. in the upper part of the lower ice-cloud layer. A possible interpretation is that the maximum cloud formation was occurring around $12-12.5 \mathrm{~km}$ where the degree of supersaturation is a maximum, but the sedimentation process created the peak cloud concentration at somewhat lower altitudes, around $11.3-11.8 \mathrm{~km}$. A similar observational result is shown in Fig. 1 of Miloshevich et al. (2001). See also the related discussion by Brabec et al. (2012).

During this SOWER campaign, the Mie depolarization lidar system at 1064 and $532 \mathrm{~nm}$ described in Shibata et al. (2012) was operated at Biak. On 27 February, the lidar data show that after 16:00 LT, a lower tropospheric cloud layer started to develop below $2 \mathrm{~km}$, often preventing the lidar from measuring cloud layers in the middle-upper tropo- 

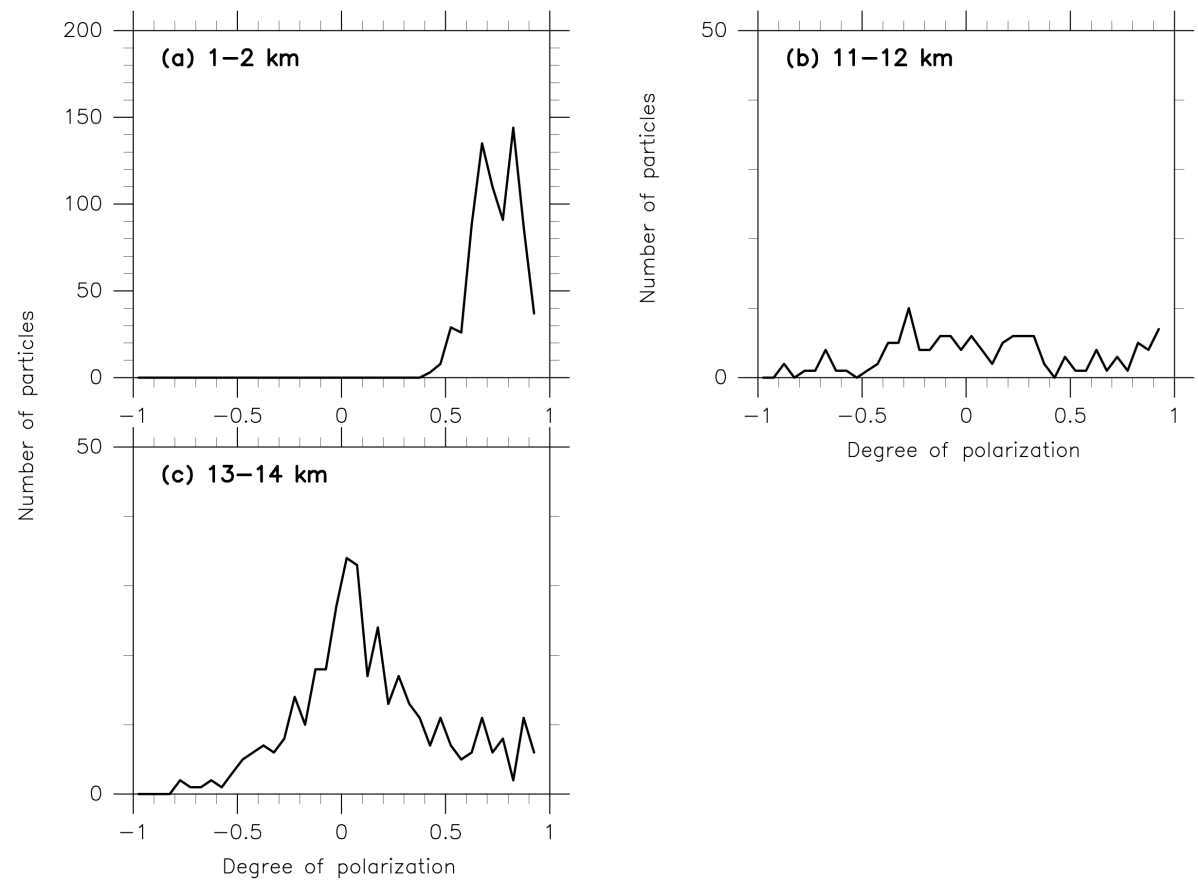

Figure 10. As for Fig. 7, but from the results shown in Fig. 9 at (a) 1-2 km (water clouds), (b) 11-12 km (ice clouds), and (c) 13-14 km (ice clouds).

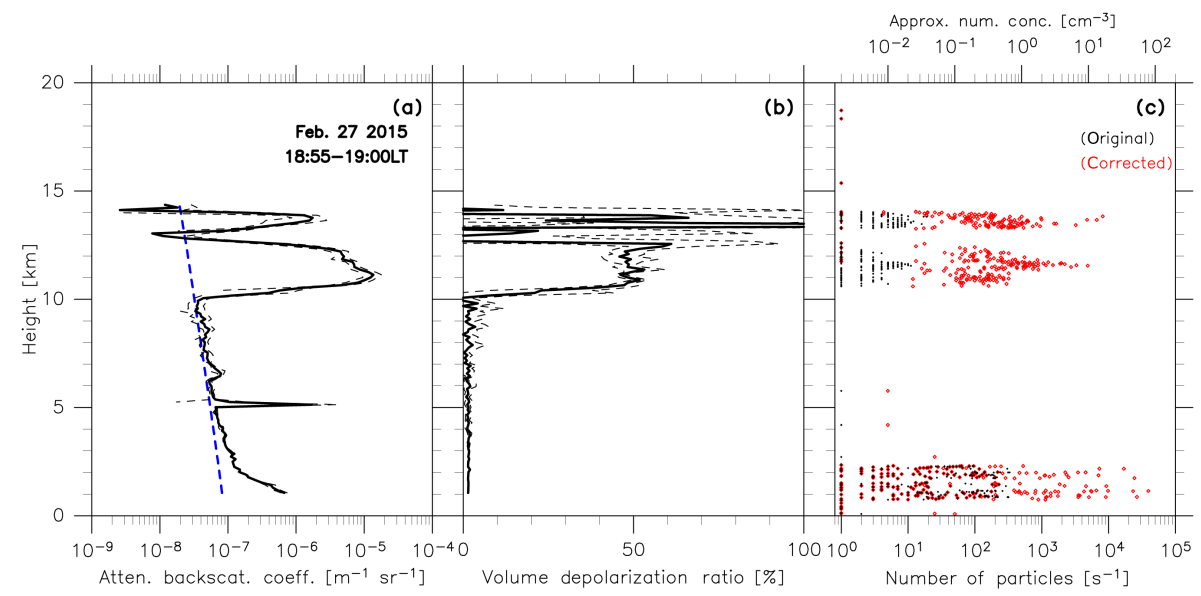

Figure 11. Vertical profiles of (a) backscattering coefficient at $1064 \mathrm{~nm}$ (thick black) and (b) depolarization ratio at $532 \mathrm{~nm}$ (thick black; see Shibata et al., 2012, for its definition) observed by a lidar system at Biak averaged over 18:55-19:00 LT on 27 February 2015; (c) the same panel as Fig. 8b (i.e. quasi-simultaneous CPS measurements). The dashed blue curve in (a) indicates the estimated contribution of air molecules due to Rayleigh scattering. The thin dashed black curves in (a) and (b) indicate the standard deviation range. Lidar data at 0-2 km and above $14 \mathrm{~km}$ are not shown because signals were saturated for the former and data were highly noisy for the latter.

sphere. Figure 11 shows the profiles of attenuated backscattering coefficient and volume depolarization ratio obtained from the lidar averaged for 5 min over 18:55-19:00 LT when the lidar obtained relatively stable and good-quality data for the upper cirrus layers through the lower tropospheric cloud layer. The balloon was located at $\sim 18 \mathrm{~km}$ at this time. The lidar data at $0-2 \mathrm{~km}$ were saturated and not suitable for scientific discussion. The lidar shows two distinct ice-cloud layers at $10.5-12.5$ and at $13.5-14 \mathrm{~km}$ with non-zero depolarization of $\sim 50$ and $\sim 60 \%$ (the latter with large variations), respectively (i.e. indicative of ice crystals). Also, the lidar does not show any clear cloud signals around $5-9 \mathrm{~km}$. These results are qualitatively consistent with the CPS measurements described above. Note that a close investigation of lidar data indicates that the thin water cloud layer at $5 \mathrm{~km}$ observed only by the lidar was quite variable in time (and thus inhomoge- 
neous in horizontal). This is the reason why there was no cloud particle where and when the balloon passed $5 \mathrm{~km}$.

In summary, the CPS in this flight successfully captured both lower tropospheric water clouds and upper tropospheric thin cirrus cloud layers in the tropics. Furthermore, the CPS measurements were consistent with the co-located lidar measurements in the middle-upper troposphere. Ground-based lidar systems are powerful tools for continuous cloud measurements (e.g. Fujiwara et al., 2009; Shibata et al., 2012). However, they have difficulties in measuring middle-upper tropospheric clouds when there are dense cloud layers in the lower troposphere. Balloon instruments such as the CPS can be complementary or even essential for cloud measurements throughout the troposphere.

\section{Conclusions}

We have developed a balloon-borne small-mass $(\sim 200 \mathrm{~g})$ CPS, which is flown with a Meisei RS-06G or RS-11G radiosonde (and potentially with other radiosondes from other manufacturers). The CPS is equipped with a near-infrared diode laser and two photodetectors, one of which has a polarization plate in front of it. The CPS can detect particles larger than $\sim 2 \mu \mathrm{m}$. The ambient air is introduced by balloon ascent-descent motion into the detection area within the instrument. The main output data from the CPS include the number of particles counted per second and, for each particle, the scattered light signals from the two detectors $\left(I_{55}\right.$ and $I_{125 \mathrm{p}}$, where $I_{125 \mathrm{p}}$ is the one from the detector with the polarization plate) and the particle signal width value. In practice, due to the limited radiosonde downlink speed for Meisei radiosondes, $I_{55}, I_{125 \mathrm{p}}$, and the signal width values are transmitted only for the first six particles coming into the detection area each second. (Note that some radiosondes from other manufacturers have greater downlink rate and that it is technically possible to develop an interface board with these radiosondes.) Using the $I_{55}$ and $I_{125}$ values, we have defined the DOP, which can be used to distinguish between water and ice-cloud particles. Results from flight tests and laboratory experiments showed the following relationship between the DOP and cloud particle phase. When the DOP value is negative, the particle is ice. When the DOP value is positive but less than $\sim 0.3$, the particle is most likely ice. When the DOP value is more than $\sim 0.3$, the particle is water in many cases, but there is a chance that it is ice (because DOP can take values between -1 and +1 for ice particles); for the final judgement, the DOP statistics of the cloud layer to which the particle is belong and the simultaneous temperature value should also be taken into account. It is noted that coarse-mode aerosol particles may give similar DOP values to ice particles. The signal width values can be used to monitor potential particle overlap and counting loss and potentially to infer the flow speed in the detection area. We have also made extensive laboratory measurements to determine the relationship between the $I_{55}$ value and water or ice diameter. For example, $I_{55}$ values of $\sim 1.3$ and $\sim 2.2 \mathrm{~V}$ correspond to $\sim 27$ and $40 \mu \mathrm{m}$ diameter water droplets, respectively (see Appendix A for the details). It should be noted that even when $I_{55}$ is saturated (i.e. for large particles), the DOP distribution can still be used for cloud-phase distinction.

If the flow speed in the detection area is known, the number of particles counted per second can be converted to the particle number concentration. Some test flights confirmed that the balloon ascent rate can be used as a first approximation, but this assumption may cause uncertainty of a factor of $\sim 2$ in the estimated number concentration. Furthermore, the maximum number concentration that can be directly measured is considered to be limited by the non-zero volume of the detection area, which is $\sim 0.5 \mathrm{~cm}^{3}$. Thus, when the particle number concentration is close to or more than $\sim 2 \mathrm{~cm}^{-3}$, more than one particle would exist simultaneously in the detection area resulting in particle overlap and multiple scattering and thus a counting loss. The particle signal width value can be used to check whether particle signal overlap is occurring or not. If it is much greater than $\sim 1 \mathrm{~ms}$, particle overlap and counting loss are occurring. Even in such a case, a correction of the number of particles or number concentration is possible by using the signal width value. In this paper, we used a simple approach for this correction. Future studies will pursue more accurate correction methods, including consideration of the statistical distribution of particles in the detection area.

We have conducted a total of 25 test flights between 2012 and 2015 at various midlatitude and tropical sites. In the paper we have shown the results from four flights that cover all the major aspects of the CPS performance. A dual flight of two CPSs with different instrumental configurations confirmed the robustness of the measurement technique and the improved performance of the CPS with the latest configuration. It was also confirmed that the CPS works very well under various atmospheric conditions such as within midlatitude precipitating cloud systems and in the wide temperature range from +30 down to $-80^{\circ} \mathrm{C}$ in the tropics. The DOP values were found to be very useful for distinguishing between water clouds (DOP values distributed between +0.5 and +1 ) and ice clouds (DOP values widely distributed within \pm 1 ). In one midlatitude flight there was a case where the DOP distribution was a combination of the water cloud and ice-cloud distributions. Considering also the temperature range of this cloud layer $\left(\sim 0\right.$ to $\left.\sim-20^{\circ} \mathrm{C}\right)$, it was concluded that the observed cloud layer was a mixed-phase cloud layer. Thus, the CPS is capable of detecting mixed-phase clouds as well as water clouds and ice clouds. It should be noted that there is limitation of detecting mixed-phase clouds. If the ice-liquid particle ratio is too small (e.g. less than $10^{-2}$ ), CPS probably cannot detect mixed-phase clouds from the viewpoint of probability theory (e.g. CPS has passed through a layer of mixed-phase cloud without catching ice particles). 
The CPS is a small-mass instrument and suitable for flying with an operational radiosonde with a small weather balloon. It can detect cloud layers and their phase, including the mixed phase. It can also provide particle number concentration if the flow speed within the instrument is known. In dense cloud layers, however, a correction for counting loss is needed using the signal width data (and probably the DC data as well). Developing a more accurate correction method, based on e.g. intercomparisons with other, well-characterised instruments, is an area for future research. We have also provided the results from extensive laboratory experiments to determine the relationship between $I_{55}$ and the diameter of water or spherical ice particles. This information would be useful to further convert the number concentration information to water content information. Finally, it should be noted that because the CPS uses a light scattering method, daytime soundings often suffer from contamination by stray sunlight that gives noisier CPS output data. If the CPS needs to be flown during the daytime, it is advised that some measures to reduce contamination by stray sunlight be considered, such as avoiding high solar elevation angles and installing longer (and non-straight) inlet and outlet ducts. (As the two detectors are looking down for the CPS, additional duct installed at the bottom is also important.) It is also noted that if very long and/or non-straight ducts are used, the flow speed in the detection area might be much smaller than the balloon ascent-descent rate. The four flights described in this paper were all conducted at dusk.

\section{Data availability}

Data are available upon request to the first author. 
Table A1. Standard spherical particles used in the laboratory experiments.

\begin{tabular}{|c|c|c|}
\hline $\begin{array}{l}\text { Diameter } \\
(\mu \mathrm{m})\end{array}$ & Material & $\begin{array}{l}\text { Refractive index* at } 775 \mathrm{~nm} \text {, } \\
\text { and at } 810 \mathrm{~nm}\end{array}$ \\
\hline 1 & polystyrene & $1.5792+0.0 \mathrm{i}, 1.5778+0.0 \mathrm{i}$ \\
\hline $2,5,10,20$ & $\begin{array}{l}\text { borosilicate } \\
\text { glass }\end{array}$ & $1.5359+0.0 \mathrm{i}, 1.5351+0.0 \mathrm{i}$ \\
\hline $30,60,100$ & $\begin{array}{l}\text { soda lime } \\
\text { glass }\end{array}$ & $\begin{array}{l}1.5177+2.1495 \times 10^{-6} \mathrm{i} \\
1.5170+2.6170 \times 10^{-6} \mathrm{i}\end{array}$ \\
\hline
\end{tabular}

* Refractive index information (as dispersion formula) was taken from http://refractiveindex.info/ (accessed on 25 February 2016). For the borosilicate glass, the values for Schott ZERODUR glass were used.

\section{Appendix A: Laboratory experiments using standard spherical particles}

Various types of standard spherical particles were used to determine the lower detection limit and the relationship between the $I_{55}$ value and the water or ice diameter for the latest version of the CPS. The $I_{125 \mathrm{p}}$ values are not used for the diameter estimation. Three CPS instruments (referred to as nos. 1, 2, and 3 here) were used to evaluate instrument-byinstrument variability. Table A1 summarizes the information on the standard spherical particles used in the laboratory experiments. In the experiments, the air was not vacuumed. We used a special apparatus to introduce the particles separately with a fan that pushes air downward into the CPS.

Mie scattering theory (Bohren and Huffman, 1998) was used to convert the diameters of the standard spherical particles to those of spherical water droplets and those of hypothetical spherical ice particles. The refractive index values used for water were obtained from Hale and Querry (1997) by linear interpolation (e.g. 1.3300+1.4800 × $10^{-7} \mathrm{i}$ at $775 \mathrm{~nm}$ and $1.3290+1.25 \times 10^{-7} \mathrm{i}$ at $\left.810 \mathrm{~nm}\right)$. For ice, we used the values obtained from Warren and Brandt (2008) (a table can be downloaded from http://www. atmos.washington.edu/ice_optical_constants/, accessed on 15 April 2016) by linear interpolation (e.g. $1.3054+9.39 \times$ $10^{-8} i$ at $775 \mathrm{~nm}$ and $1.3047+1.4 \times 10^{-7} i$ at $810 \mathrm{~nm}$ ). We calculated the scattering matrix element $S_{11}$ and $S_{12}$ of Bohren and Huffman (1998) for scattering angles $55^{\circ} \pm 10^{\circ}$ (integrated over this solid angle range) and for laser wavelengths between 775 and $810 \mathrm{~nm}$ at $1 \mathrm{~nm}$ step for each standard particle. The quantity $\left(S_{11}+S_{12}\right)$ is proportional to the scattering intensity because of the parallel polarized incident light. We took the range of laser light wavelength to be $775-810 \mathrm{~nm}$, though this is actually the instrument-by-instrument variability (see Sect. 2.1). For each standard particle, at each wavelength, we determined the diameter (or diameters) of water or ice particle that gives the same $\left(S_{11}+S_{12}\right)$ value. Then, we took the minimum and maximum diameter values for the $775-810 \mathrm{~nm}$ range, which are shown in Table A2. The aver- age of the minimum and maximum values are considered as the most probable value for simplicity.

Table A3 shows the results of the laboratory experiments. The number of particles measured ranges from $\sim 230$ to $\sim 2700$ depending on the instruments and the standard particles. It is found that the CPS is not sensitive to the $1 \mu \mathrm{m}$ standard particles (i.e. $\sim 1.36 \mu \mathrm{m}$ water and $\sim 1.42 \mu \mathrm{m}$ ice particles), that the CPS gives $\sim 0.6-0.8 \mathrm{~V} I_{55}$ for $2-10 \mu \mathrm{m}$ standard particles (i.e. $\sim 2.10-13.52 \mu \mathrm{m}$ water and 2.20 $13.83 \mu \mathrm{m}$ ice particles) without clear separation, and that the CPS gives $\sim 1.33$ and $\sim 2.17 \mathrm{~V} \mathrm{I}_{55}$ for 20 and $30 \mu \mathrm{m}$ standard particles, respectively $(\sim 26.65 \mu \mathrm{m}$ water and $\sim 28.30 \mu \mathrm{m}$ ice, and $\sim 39.50 \mu \mathrm{m}$ water and $\sim 42.29 \mu \mathrm{m}$ ice, respectively). For 60 and $100 \mu \mathrm{m}$ standard particles (i.e. $\sim 79.78$ and $\sim 132.87 \mu \mathrm{m}$ water and $\sim 85.74$ and $\sim 143.49 \mu \mathrm{m}$ ice), the CPS often gave saturated $I_{55}(53-63(83-90 \%)$ of the 60 (100) $\mu \mathrm{m}$ particles gave more than $7.1 \mathrm{~V}_{55}$ ); as Table A3 shows, however, the average and standard deviation values, calculated by including the saturated $I_{55}$ values as well, might still be useful to infer the water or ice particle diameters, at least statistically, for these ranges. Figure A1 shows the relationship between $I_{55}$ and the diameters of spherical water droplets and hypothetical spherical ice particles. It should be noted that the actual frequency distribution of $I_{55}$ for each size of particles is not normal nor symmetric but skewed; this is the reason why the horizontal bars for 60 and $100 \mu \mathrm{m}$ exceed the saturated value of $\sim 7.5 \mathrm{~V}$. This information can be used when $I_{55}$ values are converted to the diameters of spherical water or ice particles. In practice, a linear interpolation may be used for the $I_{55}$ range between 1.33 and $5.36 \mathrm{~V}$ to obtain the diameter of water or ice particle. For the ranges below 1.33 and above $5.36 \mathrm{~V}$, the uncertainty would be high for the diameter estimation.

Finally, in Fig. A2, we show the DOP distributions obtained from the standard spherical particle experiments. The results for the 5-30 $\mu \mathrm{m}$ particles are quite similar to the flight results for water clouds shown in Figs. 4a, 7a, and 10a, namely, being distributed mostly at $0.3-1$. For the smallest, $2 \mu \mathrm{m}$ particles, the distribution is longer tailed to smaller (and negative) DOP values. For the 60 and $100 \mu \mathrm{m}$ particles, whose $I_{55}$ value was often saturated as described above, the distribution still resembles those for the 5-30 $\mu \mathrm{m}$ particles although it is somewhat longer tailed to smaller (but positive) DOP values. 
Table A2. Conversion of the diameter of standard spherical particles to those of spherical water droplets and hypothetical spherical ice particles. In the third and fourth columns, the minimum, maximum, and the average of the two are shown in each table element.

\begin{tabular}{llll}
\hline $\begin{array}{l}\text { Diameter of standard } \\
\text { particles }(\mu \mathrm{m})\end{array}$ & Material & $\begin{array}{l}\text { Diameters for } \\
\text { water }(\mu \mathrm{m})\end{array}$ & $\begin{array}{l}\text { Diameters for } \\
\text { ice }(\mu \mathrm{m})\end{array}$ \\
\hline 1 & polystyrene & $1.34,1.38,1.36$ & $1.40,1.44,1.42$ \\
2 & borosilicate glass & $2.04,2.16,2.10$ & $2.14,2.26,2.20$ \\
5 & borosilicate glass & $4.74,7.12,5.93$ & $5.00,7.42,6.21$ \\
10 & borosilicate glass & $10.68,15.82,13.25$ & $11.28,16.38,13.83$ \\
20 & borosilicate glass & $23.36,29.94,26.65$ & $24.82,31.78,28.30$ \\
30 & soda lime glass & $36.78,42.22,39.50$ & $39.50,45.08,42.29$ \\
60 & soda lime glass & $77.94,81.62,79.78$ & $84.16,87.32,85.74$ \\
100 & soda lime glass & $130.14,135.60,132.87$ & $141.74,145.24,143.49$ \\
\hline
\end{tabular}

Table A3. Results from the laboratory experiments on the $I_{55}$ values for three CPS instruments (nos. 1, 2, and 3 ) for various standard spherical particles. In each table element for individual CPS instruments and for the summary column, the average $I_{55}(\mathrm{~V})$, its standard deviation, and the number of particles used in each experiment are shown. For the 10 and $20 \mu \mathrm{m}$ standard particles, two sets of experiments were conducted on different days. The summary results in the fifth column have been obtained by combining the results from all the three instruments.

\begin{tabular}{lllll}
\hline $\begin{array}{l}\text { Standard } \\
\text { particle }(\mu \mathrm{m})\end{array}$ & CPS no. 1 & CPS no. 2 & CPS no. 3 & Summary \\
\hline 1 & & & & \\
2 & (not sensitive) & (not sensitive) & (not sensitive) & (not sensitive) \\
5 & $0.674,0.349,869$ & $0.678,0.697,967$ & $0.612,0.505,1382$ & $0.648,0.538,3218$ \\
10 & $0.900,0.833,1953$ & $0.850,0.979,2264$ & $0.663,0.684,2717$ & $0.791,0.838,6934$ \\
& $0.650,0.317,1382$ & $0.673,0.551,1246$ & $0.691,0.547,1210$ & $0.717,0.557,8037$ \\
20 & $0.809,0.477,1399$ & $0.752,0.678,1205$ & $0.721,0.675,1595$ & \\
& $1.45,1.11,594$ & $1.34,1.34,631$ & $1.38,1.35,668$ & $1.33,1.24,3426$ \\
30 & $1.32,1.05,462$ & $1.20,1.17,476$ & $1.27,1.31,595$ & \\
60 & $2.39,1.81,813$ & $2.12,1.81,887$ & $1.93,1.83,612$ & $2.16,1.82,2312$ \\
100 & $5.59,2.49,1053$ & $5.41,2.71,432$ & $4.57,3.10,331$ & $5.36,2.68,1816$ \\
& $6.81,1.61,502$ & $6.36,2.18,271$ & $6.68,1.74,282$ & $6.66,1.79,1055$ \\
\hline
\end{tabular}

\section{Appendix B: Measurements of the flow speed within the CPS}

To measure the flow speed within the CPS during the flight, hot-wire anemometers of a constant-temperature type were developed (e.g. Kasagi et al., 1997). A thermistor with a spheroid shape (maximum $\sim 0.43 \mathrm{~mm}$ diameter and $\sim 0.8 \mathrm{~mm}$ length) is used for the electrically heated part, which is assumed to be in thermal equilibrium between electrical heating and convective cooling to the ambient air, as follows:

$I^{2} R=\left(T_{\mathrm{t}}-T_{\mathrm{a}}\right) \pi l \lambda \cdot N u$

where $I$ is input electric current, $R$ is resistance of the thermistor, $T_{\mathrm{t}}$ and $T_{\mathrm{a}}$ are temperatures of the thermistor and ambient air, respectively, $l$ is the length of the heated part, $\lambda$ is thermal conductivity, and $N u$ is the Nusselt number. $N u$ can be related to the Reynolds number (thus, flow speed), and we followed the discussion by Collis and Williams (1959) and used the following formulation:

$I^{2} R=\left(T_{\mathrm{t}}-T_{\mathrm{a}}\right) \times\left(A+B(\rho U)^{m}\right)$, where $A, B$, and $m$ are the coefficients to be determined by laboratory experiments, $\rho$ is air density, and $U$ is air flow speed. This is a constant-temperature type, so that $R$ (and thus $T_{\mathrm{t}}$ ) are kept constant (at $330 \Omega$ ). Therefore, we obtain $U$ from the measurements of $I, T_{\mathrm{a}}$, and $\rho$.

The coefficients $A, B$, and $m$ were determined for various upper-air conditions by two sets of laboratory experiments. One is to use a fan, an air duct, and an AM-095 anemometer provided by RION Co. Ltd under room temperature and pressure conditions. The other is to use a thermostatic chamber at Meisei Co. Ltd, at pressures 1000, 500, 250, 125, 60, and $30 \mathrm{hPa}$ at $+25^{\circ} \mathrm{C}$ and at temperatures $-40,-20,-3$, and $+25^{\circ} \mathrm{C}$ at $1000 \mathrm{hPa}$. A rotating apparatus to hold the anemometer was developed and situated in the chamber, so that the air flow speed onto the anemometer was known from the angular velocity of the rotating system. The total uncertainty of the anemometer has been evaluated to be $\pm 1 \mathrm{~m} \mathrm{~s}^{-1}$ $(k=2)$.

Two of the hot-wire anemometer explained above were placed within a $6 \mathrm{~cm}$ long duct (with a similar inner cross section to that of the CPS's air inlet), near the two open- 


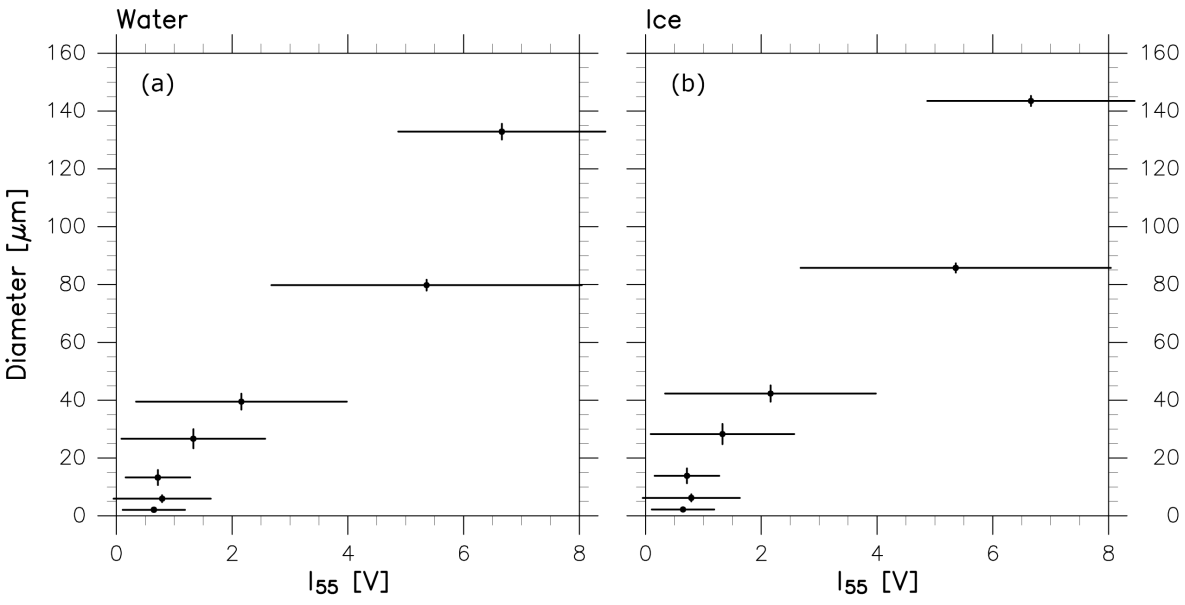

Figure A1. Relationship between $I_{55}$ and the diameters of spherical water droplets (left) and hypothetical spherical ice particles (right) based on Table A2 and the summary column of Table A3. The horizontal bars indicate the standard deviation range obtained from the laboratory experiments, while the vertical bars indicate the minimum and maximum diameters obtained from the Mie scattering calculations.
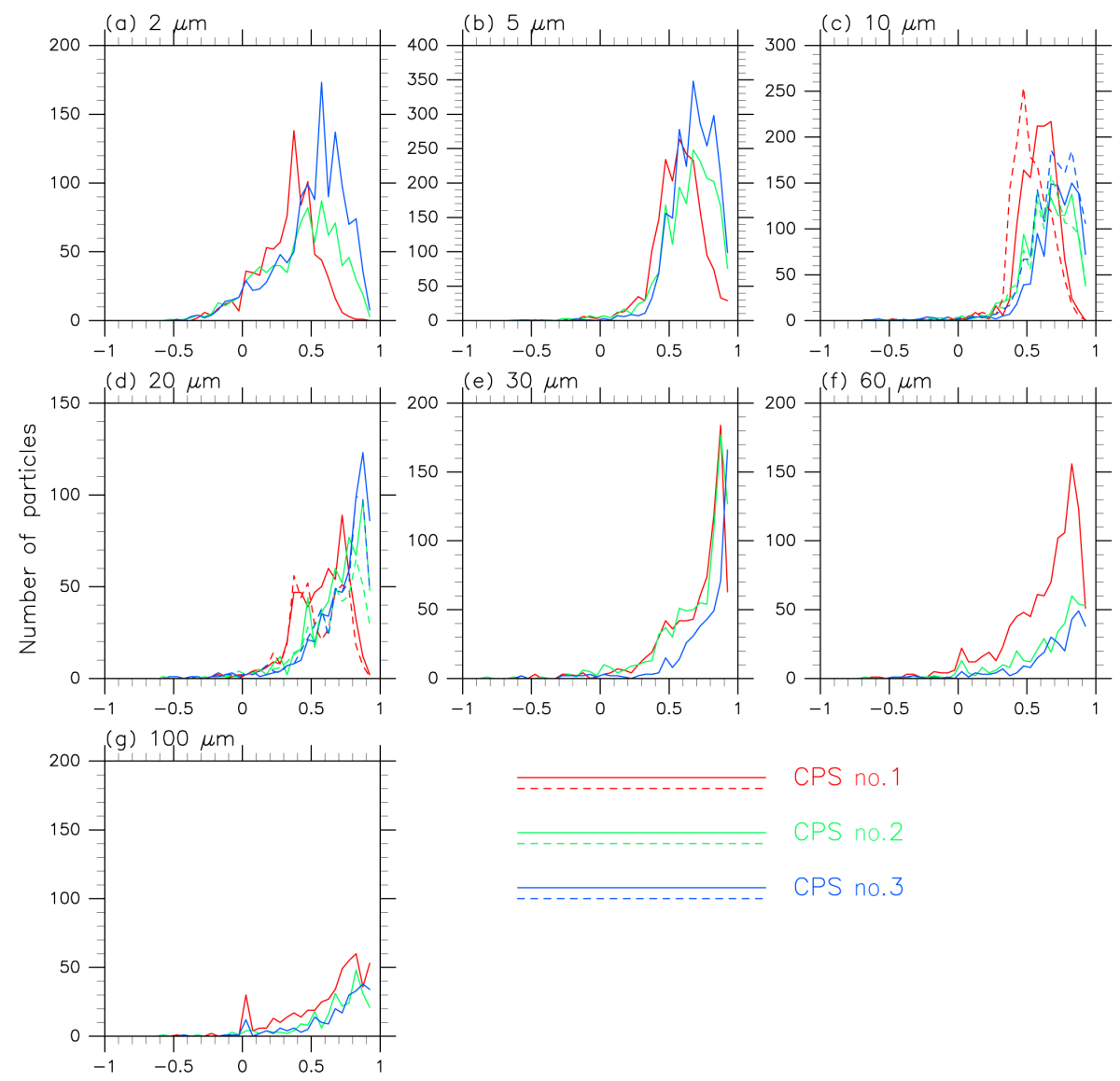

Degree of polarization

Figure A2. Frequency distributions of the degree of polarization (DOP) in 0.05 bins from the laboratory experiments using the standard spherical particles of (a) $2 \mu \mathrm{m}$, (b) $5 \mu \mathrm{m}$, (c) $10 \mu \mathrm{m}$, (d) $20 \mu \mathrm{m}$, (e) $30 \mu \mathrm{m}$, (f) $60 \mu \mathrm{m}$, and (g) $100 \mu \mathrm{m}$ diameters. Red, green, and blue curves are for the CPS nos. 1, 2, and 3 instruments, respectively. For the 10 and $20 \mu \mathrm{m}$ particles (c, d), two sets of experiments on different days are expressed with solid and dotted curves. 


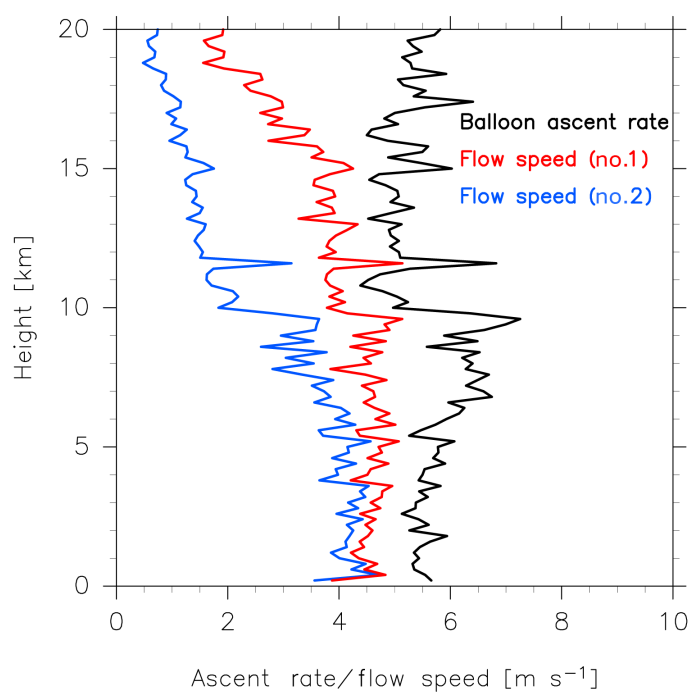

Figure B1. Vertical profiles of balloon ascent rate (black) and the flow speed within a duct (with a similar inner cross section to that of the CPS's air inlet) attached to a CPS measured with two hot-wire anemometers, one placed $\sim 4 \mathrm{~cm}$ below the detection area (no. 1, red) and the other $\sim 10 \mathrm{~cm}$ below the detection area (no. 2, blue). Taken at Moriya, Japan, launched at 17:11:47 LT on 23 November 2012. For all three profiles, $0.2 \mathrm{~km}$ averages were taken.

ings, and this duct was attached at the bottom side of a CPS. Thus, the anemometer no. 1 is located $\sim 4 \mathrm{~cm}$ below the detection area, and the anemometer no. 2 is $9-10 \mathrm{~cm}$ below the detection area. This CPS was flown at Moriya, Japan, at 17:11:47 LT on 23 November 2012. Figure B1 compares the balloon ascent rate and the flow speed measured with the two anemometers. From the surface up to $\sim 10 \mathrm{~km}$, the balloon ascent rate is $5-6 \mathrm{~m} \mathrm{~s}^{-1}$, flow speed measured by the anemometer no. 1 is $4-5 \mathrm{~m} \mathrm{~s}^{-1}$, and flow speed for no. 2 is 3-4 $\mathrm{m} \mathrm{s}^{-1}$, with increasing discrepancy between nos. 1 and 2 at higher altitudes. Between 10 and $16 \mathrm{~km}$, the balloon ascent rate is $\sim 5 \mathrm{~m} \mathrm{~s}^{-1}$, flow speed for no. 1 is $\sim 4 \mathrm{~m} \mathrm{~s}^{-1}$, and flow speed for no. 2 is $1-2 \mathrm{~m} \mathrm{~s}^{-1}$. It is expected that the actual flow speeds for nos. 1 and 2 would not differ because of the same cross section of the air flow. However, the measurement results show that this was not the case. Possible reasons include the horizontal difference in the flow rate within the duct and in the location of the two anemometers (i.e. the anemometer no. 2 may have been located closer to the duct wall during the flight). Also, these anemometers might have had some directivity dependence, which had not been evaluated in the laboratory experiments. As described in the text, we also made another test flight at Moriya on 12 October 2011 measuring flow speeds within various ducts with different cross sections using the same type of hot-wire anemometers. The results are shown in Sect. 3.2.4 of Sugidachi (2014).
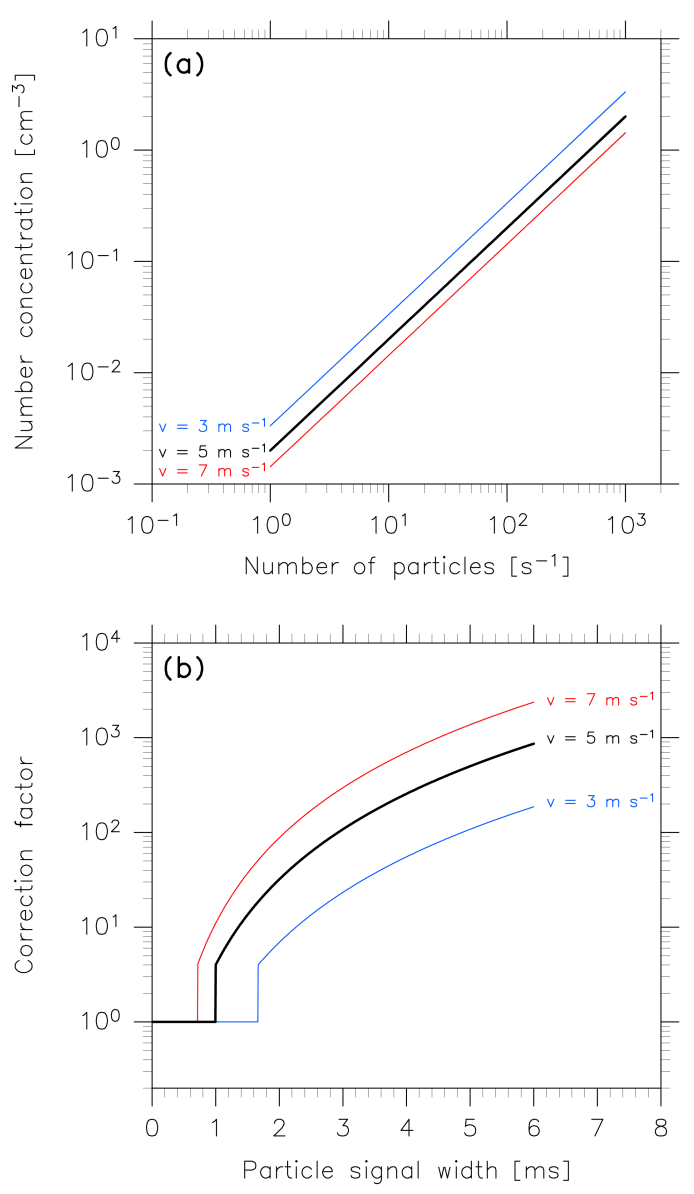

Figure C1. Dependence on the flow speed within the detection area $\left(v\right.$ in $\mathrm{m} \mathrm{s}^{-1}$ ) for (a) the conversion from number of particles in $\mathrm{s}^{-1}$ to number concentration in $\mathrm{cm}^{-3}$ and (b) the correction factor for the number of particles $\left(N\right.$ in $\left.\mathrm{s}^{-1}\right)$ with respect to the particle signal width values in ms. Shown are for $5 \mathrm{~m} \mathrm{~s}^{-1}$ (black), $3 \mathrm{~m} \mathrm{~s}^{-1}$ (blue), and $7 \mathrm{~m} \mathrm{~s}^{-1}$ (red).

\section{Appendix C: Dependence on the flow speed for the number density conversion and for the count number correction}

Both the conversion from number of particles $N\left(\mathrm{~s}^{-1}\right)$ to number concentration $C\left(\mathrm{~cm}^{-3}\right)$ and the correction factor for $N$ depend on the flow speed within the detection area $v$ $\left(\mathrm{m} \mathrm{s}^{-1}\right)$. As the cross section of the detection area is $\sim 1 \mathrm{~cm}^{2}$, $C$ is given by $N /(100 v)$. As the vertical extent of the detection area is $\sim 0.5 \mathrm{~cm}$, the correction factor for $N$ (see discussion in Sect. 2.3) is $4 \times(\mathrm{psw} /(5 / v))^{3}$ if psw is greater than $5 / v$, where psw is particle signal width in ms; if psw is smaller than $5 / v$, the correction factor is unity. Figure $\mathrm{C} 1$ shows the relationships between $N$ and $C$ and between psw and the correction factor for $v=3,5$, and $7 \mathrm{~m} \mathrm{~s}^{-1}$. This indicates the contribution of the uncertainty in $v$ (see also Appendix B) to the uncertainty in (corrected) $N$. 
Acknowledgements. Balloon flights at Moriya, Japan, were made at the Meisei test field. Balloon flights at Biak, Indonesia, were made under the Soundings of Ozone and Water in the Equatorial Region (SOWER) project in collaboration with the Indonesian National Institute of Aeronautics and Space (LAPAN). Balloon flights were also made at Palau and at Tateno by the Hydrospheric-Atmospheric Research Center, Nagoya University, and by the Japan Meteorological Agency, respectively, and their data contributed to the understanding of the CPS performance. This study was financially supported by the Japanese Ministry of Education, Culture, Sports, Science and Technology (MEXT) through grants-in-aid for scientific research $(21244072,22740306,26220101$, and 26630448) and by the Institute of Space and Astronautical Science (ISAS) of Japan Space Exploration Agency (JAXA) through the Steering Committee for Space Science (SCSS). Figures 3-11, A1-A2, B1, and $\mathrm{C} 1$ were produced using the GFD-DENNOU Library. We thank D. Baumgardner, F. G. Wienhold, and an anonymous referee for valuable comments and suggestions.

Edited by: M. Wendisch

Reviewed by: F. G. Wienhold, D. Baumgardner, and one anonymous referee

\section{References}

Baumgardner, D., Avallone, L., Bansemer, A., Borrmann, S., Brown, P., Bundke, U., Chuang, P. Y., Cziczo, D., Field, P., Gallagher, M., Gayet, J.-F., Heymsfield, A., Korolev, A., Krämer, M., McFarquhar, G., Mertes, S., Möhler, O., Lance, S., Lawson, P., Petters, M. D., Pratt, K., Roberts, G., Rogers, D., Stetzer, O., Stith, J., Strapp, W., Twohy, C., and Wendisch, M.: In situ, airborne instrumentation: Addressing and solving measurement problems in ice clouds, B. Am. Meteor. Soc., 93, ES29-ES34, doi:10.1175/BAMS-D-11-00123.1, 2012.

Baumgardner, D., Newton, R., Krämer, M., Meyer, J., Beyer, A., Wendisch, M., and Vochezer, P.: The Cloud Particle Spectrometer with Polarization Detection (CPSPD): A next generation open-path cloud probe for distinguishing liquid cloud droplets from ice crystals, Atmos. Res., 142, 2-14, doi:10.1016/j.atmosres.2013.12.010, 2014.

Bohren, C. F. and Huffman, D. R.: Absorption and scattering of light by small particles, Wiley, New York, USA, 530 pp., 1998.

Brabec, M., Wienhold, F. G., Luo, B. P., Vömel, H., Immler, F., Steiner, P., Hausammann, E., Weers, U., and Peter, T.: Particle backscatter and relative humidity measured across cirrus clouds and comparison with microphysical cirrus modelling, Atmos. Chem. Phys., 12, 9135-9148, doi:10.5194/acp-12-9135-2012, 2012.

Collis, D. C. and Williams, M. J.: Two-dimensional convection from heating wires at low Reynolds numbers, J. Fluid Mech., 6, 357384, doi:10.1017/S0022112059000696, 1959.

Cotton, R., Osborne, S., Ulanowski, Z., Hirst, E., Kaye, P. H., and Greenaway, R. S.: The ability of the Small Ice Detector (SID-2) to characterize cloud particle and aerosol morphologies obtained during flights of the FAAM BAe-146 research aircraft, J. Atmos. Ocean. Tech., 27, 290-303, doi:10.1175/2009JTECHA1282.1, 2010.
Fujiwara, M., Hasebe, F., Shiotani, M., Nishi, N., Vömel, H., and Oltmans, S. J.: Water vapor control at the tropopause by equatorial Kelvin waves observed over the Galápagos, Geophys. Res. Lett., 28, 3143-3146, doi:10.1029/2001GL013310, 2001.

Fujiwara, M., Shiotani, M., Hasebe, F., Vömel, H., Oltmans, S. J., Ruppert, P. W., Horinouchi, T., and Tsuda, T.: Performance of the Meteolabor "Snow White" chilled-mirror hygrometer in the tropical troposphere: comparisons with the Vaisala RS80 A/HHumicap sensors, J. Atmos. Ocean. Tech., 20, 1534-1542, 2003.

Fujiwara, M., Iwasaki, S., Shimizu, A., Inai, Y., Shiotani, M., Hasebe, F., Matsui, I., Sugimoto, N., Okamoto, H., Nishi, N., Hamada, A., Sakazaki, T., and Yoneyama, K.: Cirrus observations in the tropical tropopause layer over the western Pacific, J. Geophys. Res., 114, D09304, doi:10.1029/2008JD011040, 2009.

Hale, G. M. and Querry, M. R.: Optical constants of water in the 200-nm to 200- $\mu \mathrm{m}$ wavelength region, Appl. Opt., 12, 555-563, doi:10.1364/AO.12.000555, 1973.

Hasebe, F., Inai, Y., Shiotani, M., Fujiwara, M., Vömel, H., Nishi, N., Ogino, S.-Y., Shibata, T., Iwasaki, S., Komala, N., Peter, T., and Oltmans, S. J.: Cold trap dehydration in the Tropical Tropopause Layer characterised by SOWER chilled-mirror hygrometer network data in the Tropical Pacific, Atmos. Chem. Phys., 13, 4393-4411, doi:10.5194/acp-13-4393-2013, 2013.

Hayashi, M., Iwasaka, Y., Watanabe, M., Shibata, T., Fujiwara, M., Adachi, H., Sakai, T., Nagatani, M., Gernandt, H., Neuber, R., and Tsuchiya, M.: Size and number concentration of liquid PSCs: balloon-borne measurements at Ny-Ålesund, Norway in winter of 1994/1995, J. Meteorol. Soc. Jpn., 76, 549-560, 1998.

Hyland, R. W. and Wexler, A.: Formulations for the thermodynamic properties of the saturated phases of $\mathrm{H}_{2} \mathrm{O}$ from $173.15 \mathrm{~K}$ to 473.15 K, ASHRAE Trans., 89, 500-519, 1983.

Inai, Y., Shibata, T., Fujiwara, M., Hasebe, F., and Vömel, H.: High supersaturation inside cirrus in well-developed tropical tropopause layer over Indonesia, Geophys. Res. Lett., 39, L20811, doi:10.1029/2012GL053638, 2012.

Iwasaki, S., Tsushima, Y., Shirooka, R., Katsumata, M., Yoneyama, K., Matsui, I., Shimizu, A., Sugimoto, N., Kamei, A., Kuroiwa, H., Kumagai, H., and Okamoto, H.: Subvisual cirrus cloud observations using a 1064-nm lidar, a $95 \mathrm{GHz}$ cloud radar, and radiosondes in the warm pool region, Geophys. Res. Lett., 31, L09103, doi:10.1029/2003GL019377, 2004.

Iwasaki, S., Maruyama, K., Hayashi, M., Ogino, S.-Y., Ishimoto, H., Tachibana, Y., Shimizu, A., Matsui, I., Sugimoto, N., Yamashita, K., Saga, K., Iwamoto, K., Kamiakito, Y., Chabangborn, A., Thana, B., Hashizume, M., Koike, T., and Oki, T.: Characteristics of aerosol and cloud particle size distributions in the tropical tropopause layer measured with optical particle counter and lidar, Atmos. Chem. Phys., 7, 3507-3518, doi:10.5194/acp7-3507-2007, 2007.

Kasagi, N., Kimura, R., Nishioka, M., Hino, M., and Yasuhara, M. (Eds.): Ryuutai Jikken Handbook (Fluid Experiment Handbook, in Japanese), Asakura Shoten, Tokyo, Japan, 709 pp., 1997.

Magono, C. and Tazawa, S.: Design of "snow crystal sondes", J. Atmos. Sci., 23, 618-625, 1966.

Miloshevich, L. M. and Heymsfield, A. J.: A balloon-borne continuous cloud particle replicator for measuring vertical profiles of cloud microphysical properties: instrument design, performance, and collection efficiency analysis, J. Atmos. Ocean. Tech., 14, 753-768, 1997. 
Miloshevich, L. M., Vömel, H., Paukkunen, A., Heymsfield, A. J., and Oltmans, S. J.: Characterization and correction of relative humidity measurements from Vaisala RS80-A radiosondes at cold temperatures, J. Atmos. Ocean. Tech., 18, 135-156, 2001.

Murakami, M. and Matsuo, T.: Development of the hydrometeor videosonde, J. Atmos. Ocean. Tech., 7, 613-620, 1990.

Murphy, D. M. and Koop, T.: Review of the vapour pressures of ice and supercooled water for atmospheric applications, Q. J. Roy. Meteor. Soc., 131, 1539-1565, doi:10.1256/qj.04.94, 2005.

Nash, J., Oakley, T., Vömel, H., and Li, W.: WMO Intercomparison of high quality radiosonde observing systems, Yangjiang, China, 12 July-3 August 2010, World Meteorological Organization Instruments and Observing Methods, Report IOM-107, WMO/TDNo. 1580, available at: https://www.wmo.int/pages/prog/www/ IMOP/publications-IOM-series.html (last access: 26 September 2016), 2011.

Nichman, L., Fuchs, C., Järvinen, E., Ignatius, K., Höppel, N. F., Dias, A., Heinritzi, M., Simon, M., Tröstl, J., Wagner, A. C., Wagner, R., Williamson, C., Yan, C., Connolly, P. J., Dorsey, J. R., Duplissy, J., Ehrhart, S., Frege, C., Gordon, H., Hoyle, C. R., Kristensen, T. B., Steiner, G., McPherson Donahue, N., Flagan, R., Gallagher, M. W., Kirkby, J., Möhler, O., Saathoff, H., Schnaiter, M., Stratmann, F., and Tomé, A.: Phase transition observations and discrimination of small cloud particles by light polarization in expansion chamber experiments, Atmos. Chem. Phys., 16, 3651-3664, doi:10.5194/acp-16-3651-2016, 2016.

Orikasa, N. and Murakami, M.: Ice crystal shapes in midlatitude cirrus clouds derived from Hydrometeor Videosonde (HYVIS) observations, J. Meteorol. Soc. Jpn., 93, 143-155, doi:10.2151/jmsj.2015-004, 2015.

Orikasa, N., Murakami, M., Hoshimoto, M., and Yamada, Y.: Re-evaluation of the collection efficiency of the Hydrometeor Videosonde for dry snow particles, J. Meteorol. Soc. Jpn., 83, 439-448, doi:10.2151/jmsj.83.439, 2005.

Orikasa, N., Murakami, M., and Heymsfield, A. J.: Ice crystal concentration in midlatitude cirrus clouds: in situ measurements with the balloonborne hydrometeor videosonde (HYVIS), J. Meteorol. Soc. Jpn., 91, 143-161, doi:10.2151/jmsj.2013-204, 2013.

Rosen, J. M. and Kjome, N. T.: Backscattersonde: a new instrument for atmospheric research, Appl. Opt., 30, 1552-1561, 1991.

Pruppacher, H. R. and Klett, J. D.: Microphysics of clouds and precipitation, Kluwer Academic Pub., Dordrecht, the Netherlands, 954 pp., 1997.

Sassen, K.: The polarization lidar technique for cloud research: A review and current assessment, B. Am. Meteorol. Soc., 72, 1848-1866, doi:10.1175/15200477(1991)072<1848:TPLTFC>2.0.CO;2, 1991.

Schotland, R. M., Sassen, K., and Stone, R.: Observations by lidar of linear depolarization ratios for hydrometeors, J. Appl. Meteorol., 10, 1011-1017, doi:10.1175/15200450(1971)010<1011:OBLOLD>2.0.CO;2, 1971.

Shibata, T., Vömel, H., Hamdi, S., Kaloka, S., Hasebe, F., Fujiwara, M., and Shiotani, M.: Tropical cirrus clouds near cold point tropopause under ice supersaturated conditions observed by lidar and balloon-borne cryogenic frost point hygrometer, J. Geophys. Res., 112, D03210, doi:10.1029/2006JD007361, 2007.

Shibata, T., Hayashi, M., Naganuma, A., Hara, N., Hara, K., Hasebe, F., Shimizu, K., Komala, N., Inai, Y., Vömel, H., Hamdi, S., Iwasaki, S., Fujiwara, M., Shiotani, M., Ogino,
S.-Y., and Nishi, N.: Cirrus cloud appearance in a volcanic aerosol layer around the tropical cold point tropopause over Biak, Indonesia, in January 2011, J. Geophys. Res., 117, D11209, doi:10.1029/2011JD017029, 2012.

Shimizu, A., Sugimoto, N., Matsui, I., Arao, K., Uno, I., Murayama, T., Kagawa, N., Aoki, K., Uchiyama, A., and Yamazaki, A.: Continuous observations of Asian dust and other aerosols by polarization lidars in China and Japan during ACE-Asia, J. Geophys. Res., 109, D19S17, doi:10.1029/2002JD003253, 2004.

Sugidachi, T.: Studies on the tropospheric and stratospheric water vapor measurements for climate monitoring, $\mathrm{PhD}$ thesis, Graduate School of Environmental Science, Hokkaido University, 138 pp., available at: http://hdl.handle.net/2115/55416 (last access: 26 September 2016), 2014.

Sugimoto, N., Matsui, I., Shimizu, A., Nishizawa, T., Hara, Y., Xie, C., Uno, I., Yumimoto, K., Wang, Z., and Yoon, S.-C.: Lidar network observations of troposheric aerosols, Proc. SPIE 7153, Lidar Remote Sensing for Environmental Monitoring IX, 71530A, doi:10.1117/12.806540, 2008.

Sugimoto, N., Shimizu, A., Matsui, I., and Nishikawa, M.: A method for estimating the fraction of mineral dust in particulate matter using $\mathrm{PM}_{2.5}$-to- $\mathrm{PM}_{10}$ ratios, Particuology, 28, 114-120, doi:10.1016/j.partic.2015.09.005, 2016.

Suortti, T., Karhu, J., Kivi, R., Kyrö, E., Rosen, J., Kjome, N., Larsen, N., Neuber, R., Khattatov, V., Rudakov, V., Yushkov, V., and Nakane, H.: Evolution of the Arctic stratospheric aerosol mixing ratio measured with balloon-borne aerosol backscatter sondes for years 1988-2000, J. Geophys. Res., 106, 20759 20766, doi:10.1029/2000JD000180, 2001.

Suzuki, K., Matsuo, M., Nakano, E., Shigeto, S., Yamaguchi, K., and Nakakita, E.: Graupel in the different developing stages of Baiu monsoon clouds observed by Videosondes, Atmos. Res., 142, 100-110, doi:10.1016/j.atmosres.2013.09.020, 2014.

Takahashi, T.: Near absence of lightning in torrential rainfall producing Micronesian thunderstorms, Geophys. Res. Lett., 17, 2381-2384, 1990.

Takahashi, T.: Precipitation mechanisms in east Asian monsoon: Videosonde study, J. Geophys. Res., 111, D09202, doi:10.1029/2005JD006268, 2006.

Vömel, H., David, D. E., and Smith, K.: Accuracy of tropospheric and stratospheric water vapor measurements by the cryogenic frost point hygrometer: instrumental details and observations, J. Geophys. Res., 112, D08305, doi:10.1029/2006JD007224, 2007.

Vömel, H., Naebert, T., Dirksen, R., and Sommer, M.: An update on the uncertainties of water vapor measurements using cryogenic frost point hygrometers, Atmos. Meas. Tech., 9, 37553768, doi:10.5194/amt-9-3755-2016, 2016.

Warren, S. G. and Brandt, R. E.: Optical constants of ice from the ultraviolet to the microwave: a revised compilation, J. Geophys. Res., 113, D14220, doi:10.1029/2007JD009744, 2008.

Wendisch, M. and Brenguier, J.-L. (Eds): Airborne Measurements for Environmental Research: Methods and Instruments, WileyVCH Verlag GmbH \& Co. KGaA, Weinheim, Germany, 655 pp., doi:10.1002/9783527653218, 2013.

Zhang, C.: Madden-Julian Oscillation, Rev. Geophys., 43, RG2003, doi:10.1029/2004RG000158, 2005. 